LA W REN CE LIVERMORE N A TIONAL LABORATORY
Spinodal Decomposition and

Order-Disorder Transformation in a Water-Quenched U-6wt\%Nb Alloy

L. Hsiung, J. Zhou

September 14, 2006 
This document was prepared as an account of work sponsored by an agency of the United States Government. Neither the United States Government nor the University of California nor any of their employees, makes any warranty, express or implied, or assumes any legal liability or responsibility for the accuracy, completeness, or usefulness of any information, apparatus, product, or process disclosed, or represents that its use would not infringe privately owned rights. Reference herein to any specific commercial product, process, or service by trade name, trademark, manufacturer, or otherwise, does not necessarily constitute or imply its endorsement, recommendation, or favoring by the United States Government or the University of California. The views and opinions of authors expressed herein do not necessarily state or reflect those of the United States Government or the University of California, and shall not be used for advertising or product endorsement purposes.

This work was performed under the auspices of the U.S. Department of Energy by University of California, Lawrence Livermore National Laboratory under Contract W-7405-Eng-48. 


\title{
SPINODAL DECOMPOSITION AND ORDER-DISORDER TRANSFORMATION IN A WATER-QUENCHED U-6wt \%Nb ALLOY
}

\author{
Luke Hsiung and Jikou Zhou
}

Materials Science and Technology Division, L-352

\section{Objectives and accomplishments}

A combinative approach of microhardness testing, tensile testing, and TEM microstructural analysis has been employed to study phase stability and aging mechanisms of a water-quenched U-6wt\%Nb (WQ$\mathrm{U} 6 \mathrm{Nb}$ ) alloy subjected to different aging schedules that include artificial aging of WQ-U6Nb at $200^{\circ} \mathrm{C}$, natural aging of WQ-U6Nb at ambient temperatures for 15 to18 years, and accelerative aging of the naturally aged (NA) alloy at $200^{\circ} \mathrm{C}$. During the early stages of artificial aging at $200^{\circ} \mathrm{C}$, the microhardness values continuously increase as a result of the development of a fine-scale compositional modulation (wavelength: $3 \mathrm{~nm}$ ) caused by spinodal decomposition. Coarsening of the modulated structure occurs after prolonged aging of $\mathrm{WQ}-\mathrm{U} 6 \mathrm{Nb}$ at $200^{\circ} \mathrm{C}$ for 16 hours, which leads to a decrease of microhardness. Phase instability has also been found to occur in the NA alloy, in which the formation of partially ordered phase domains resulting from an atomic-scale spinodal modulation (wavelength: 0.5 $\mathrm{nm}$ ) renders the appearance of antiphase domain boundaries (APBs) in TEM images. Although 18-year natural aging does not cause a significant change in hardness, it affects dramatically the aging mechanism of $\mathrm{WQ}-\mathrm{U} 6 \mathrm{Nb}$ subjected to the accelerative aging at $200^{\circ} \mathrm{C}$. The result of microhardness measurement shows that the hardness values continuously increase until after aging for 239 hours, and the total hardness increment is twice in magnitude than that in the case of the artificial aging of waterquenched alloy at $200^{\circ} \mathrm{C}$. The anomalous increment of hardness for the accelerative aging of NA alloy can be attributed to the precipitation of an ordered $\mathrm{U}_{3} \mathrm{Nb}$ phase. It is accordingly concluded that the long-term natural aging at ambient temperatures can detour the transformation pathway of WQ U-6Nb alloy; it leads to the order-disorder transformation and precipitation of ordered phase in the alloy. 


\section{Introduction and theoretical background}

It is well known that $\mathrm{U}-6 \mathrm{wt} \% \mathrm{Nb}(\mathrm{U}-14 \mathrm{at} \% \mathrm{Nb})$ alloy, as exploited for a variety of engineering applications, has a microstructure containing martensitic phases supersaturated with $\mathrm{Nb}$ that can be obtained by rapid quenching the alloy from $\gamma$ (bcc)-field solid solution to room temperature $[1,2]$. The high cooling rate forces the $\gamma$-phase solid solution to transform diffusionlessly to variants of the low temperature $\alpha$ (orthorhombic) phase in which $\mathrm{Nb}$ is forced to retain in the supersaturated solid solution. It is noted that the crystal lattice of supersaturated solution formed by rapid quenching is unstable and is severely distorted since the solubility of $\mathrm{Nb}$ in the $\alpha$ phase at room temperature is nearly zero in stable equilibrium [3]. One variant phase has been designated as $\alpha^{\prime}$ martensite because its lattice parameters differ from the $\alpha$ phase as a result of the supersaturation. Two additional variant phases, a monoclinic distortion of $\alpha^{\prime}$ phase that is designated as $\alpha^{\prime \prime}$ martensite and a tetragonal distortion of $\gamma$ phase that is designated as $\gamma^{0}$ phase, can also form within the as-quenched alloy. The alloy produced by a waterquench process, which suppresses the reaction of diffusional decomposition that leads to the formation of an undesirable two-phase [Nb-depleted $\alpha(\mathrm{U})$ phase and $\mathrm{Nb}$-enriched $\gamma$ phase] cellular microstructure, has superior mechanical properties and excellent corrosion resistance because of the uniform distribution of high $\mathrm{Nb}$ content in the supersaturated solid solution.

It has been reported that water-quenched $\mathrm{U}-6 \mathrm{wt} \% \mathrm{Nb}$ alloy containing extensively twinned $\alpha^{\prime \prime}$ martensite reveals shape memory effect and possesses low yield strength ( 200 MPa) and high tensile ductility $(\sim 30 \%)[2,4,5]$. Aging of the $\alpha^{\prime \prime}$ martensite in the range of $150^{\circ} \mathrm{C}$ to $400^{\circ} \mathrm{C}$ causes an increase of yield strength to $\sim 1.3 \mathrm{GPa}$ as a result of the formation of very fine-scale modulated structure presumably caused by spinodal decomposition [6]. Aging of the $\alpha^{\prime \prime}$ martensite at temperatures above $400^{\circ} \mathrm{C}$, where cellular decomposition $\left[\alpha^{\prime \prime} \rightarrow \alpha(\mathrm{U})+\gamma\right]$ occurs to form coarse two-phase cellular microstructures, can subsequently deteriorate and embrittle the alloy by reducing ductility and toughness as well as corrosion resistance $[2,6]$. The investigations of aging effects on WQ-U6Nb reported in the 
open literature have mainly been placed on aging at temperatures above $400^{\circ} \mathrm{C}$, relatively fewer investigations were conducted on the aging behavior of WQ-U6Nb below $400^{\circ} \mathrm{C}$. A fine-scale solute segregation occurred in isothermally aged WQ-U6Nb below $400^{\circ} \mathrm{C}$ was first reported by Beverini and Edmonds [7], who investigated the low-temperature aging behavior using microhardness measurement, atom-probe field-ion microscopy (APFIM), and transmission electron microscopy (TEM) techniques. According to their report, an age hardening phenomenon associated with nanoscale solute segregation caused by spinodal decomposition was detected. In the alloy samples aged at $300^{\circ} \mathrm{C}$ for 16 hours, $\mathrm{Nb}$ content was fluctuated between 5 at.\% and 30 at.\%, and the wavelength of composition fluctuation was determined to be $\sim 3 \mathrm{~nm}$. Noting that spinodal decomposition is a continuous clustering reaction in which the supersaturated (single-phase) solid solution decomposes into two phases which have different compositions but the same crystal structure through uphill diffusion that is different from the nucleationand-growth reaction via downhill diffusion [8-12]. It is also noted that age hardening associated with a fine-scale modulated structure in a WQ-U6Nb alloy aged at $200^{\circ} \mathrm{C}$ was also verified and reported recently in [13].

When considering the transformation of WQ-U6Nb alloy, one has to realize the fact that the supersaturated $\mathrm{U}-6 \mathrm{wt} \% \mathrm{Nb}$ (or $\mathrm{U}-14 \mathrm{at} \% \mathrm{Nb}$ ) solid solution is thermodynamically unstable; it will decompose into a mixture of two phases upon aging through either (1) nucleation-and-growth mechanism or (2) spinodal decomposition mechanism. To discern these two mechanisms of decomposition, consider a hypothetical phase diagram shown in Fig. 1a, which illustrates the miscibility gap and the region of chemical spinodal. The corresponding curve for Gibbs free energy versus composition at a given temperature $\mathrm{T}_{\mathrm{o}}$ is shown in Fig. 1b. The points of inflection in Fig. 1b, where the second derivative of the Gibbs free energy-composition curve is zero $\left[\mathrm{G}^{\prime \prime}\left(\mathrm{c}_{\mathrm{o}}\right)=0\right]$ are called spinodal points, which separate the region of concave-up $\left[\mathrm{G}^{\prime \prime}\left(\mathrm{c}_{\mathrm{o}}\right)>0\right]$ from the region of concave-down $\left[\mathrm{G}^{\prime \prime}\left(\mathrm{c}_{\mathrm{o}}\right)<\right.$ 0]. Consider the change in Gibbs free energy $(\Delta G)$ of the supersaturated solution of initial composition $c_{o}$ as it undergoes local fluctuations of $\pm \delta c$. That is, the solution decomposes into a mixture of two 
phases of composition $c_{o}+\delta c$ and $c_{o}-\delta c$. For an infinitesimal fluctuation, the Gibbs free energy of the solution can be expanded as a function of composition around the composition $\mathrm{c}_{\mathrm{o}}$ by a Taylor series:

$$
\mathrm{G}\left(\mathrm{c}_{\mathrm{o}} \pm \delta \mathrm{c}\right)=\mathrm{G}\left(\mathrm{c}_{\mathrm{o}}\right)+( \pm \delta \mathrm{c}) \mathrm{G}^{\prime}\left(\mathrm{c}_{\mathrm{o}}\right)+1 / 2( \pm \delta \mathrm{c})^{2} \mathrm{G}^{\prime \prime}\left(\mathrm{c}_{\mathrm{o}}\right)
$$

Where $\mathrm{G}^{\prime}\left(\mathrm{c}_{\mathrm{o}}\right)=(\partial \mathrm{G} / \partial \mathrm{c}) \mathrm{c}_{\mathrm{o}}$ and $\mathrm{G}^{\prime \prime}\left(\mathrm{c}_{\mathrm{o}}\right)=\left(\partial^{2} \mathrm{G} / \partial \mathrm{c}^{2}\right) \mathrm{c}_{\mathrm{o}}$. Therefore, the change in Gibbs free energy accompanying the composition fluctuation is:

$$
\begin{aligned}
& \Delta \mathrm{G}=\mathrm{G}\left(\mathrm{c}_{\mathrm{o}} \pm \delta \mathrm{c}\right)-\mathrm{G}\left(\mathrm{c}_{\mathrm{o}}\right)=1 / 2\left[\mathrm{G}\left(\mathrm{c}_{\mathrm{o}}+\delta \mathrm{c}\right)+\mathrm{G}\left(\mathrm{c}_{\mathrm{o}}-\delta \mathrm{c}\right)\right]-\mathrm{G}\left(\mathrm{c}_{\mathrm{o}}\right), \\
& \Delta \mathrm{G}=1 / 2\left[(\delta \mathrm{c}) \mathrm{G}^{\prime \prime}\left(\mathrm{c}_{\mathrm{o}}\right)+1 / 2(\delta \mathrm{c})^{2} \mathrm{G}^{\prime \prime}\left(\mathrm{c}_{\mathrm{o}}\right)\right]+1 / 2\left[(-\delta \mathrm{c}) \mathrm{G}^{\prime \prime}\left(\mathrm{c}_{\mathrm{o}}\right)+1 / 2(-\delta \mathrm{c})^{2} \mathrm{G}^{\prime \prime}\left(\mathrm{c}_{\mathrm{o}}\right)\right],
\end{aligned}
$$

and

$$
\Delta \mathrm{G}=1 / 2(\delta \mathrm{c})^{2} \mathrm{G}^{\prime \prime}\left(\mathrm{c}_{\mathrm{o}}\right)
$$

If the initial composition $c_{o}$ lies in the concave-up $\left[\mathrm{G}^{\prime \prime}\left(\mathrm{c}_{\mathrm{o}}\right)>0\right]$ region, any infinitesimal fluctuation increases the free energy, and the system is thus in a metastable state. The overall free energy of the system must be increased before transforming into a lower free-energy state can occur. The combined free energy of the decomposed solution is initially higher than the initial free energy of the solution. As the reaction proceeds, the combined free energy will eventually be less than the initial free energy, but there is an energy barrier to be overcome during the decomposition process. The decomposition of such a solution requires the nucleation-and-growth reaction. However, in the concave-down region $\left[\mathrm{G}^{\prime \prime}\left(\mathrm{c}_{\mathrm{o}}\right)<\right.$ 0], any fluctuation decreases the free energy, and the system is in an unstable state, which is the spinodal decomposition case, and the decomposition may begin without an increase in the free energy. As the solution decomposes into two phases, the combined free energy of the two resulting phases is always below the free energy of the original solution. There is no energy barrier to be overcome during the process of spinodal decomposition; the spinodal reaction is determined solely by diffusion, which can take place over a wide region, but the changes in composition are continuous and small.

In the early stages of spinodal decomposition, periodic strain-contrast striations known as the tweedlike or modulated structure accompanied with satellite diffraction spots in electron diffraction pattern 
can usually be detectable using TEM techniques $[14,15]$. The modulated structured generated from spinodal decomposition is distinctly different from the microstructure produced by a randomly nucleated and grown precipitates. In order to elucidate the low-temperature aging mechanisms and to understand the effects of long-term aging on the aging behavior of WQ-U6Nb alloy, the emphasis of this study was placed on TEM characterization and analysis of phase and microstructural changes in WQ-U6Nb alloy subjected to different aging schedules: artificial aging of WQ-U6Nb at $200^{\circ} \mathrm{C}$, natural aging of WQ$\mathrm{U} 6 \mathrm{Nb}$ at ambient temperatures for 18 years, and accelerative aging of 18-year old naturally aged alloy at $200^{\circ} \mathrm{C}$.

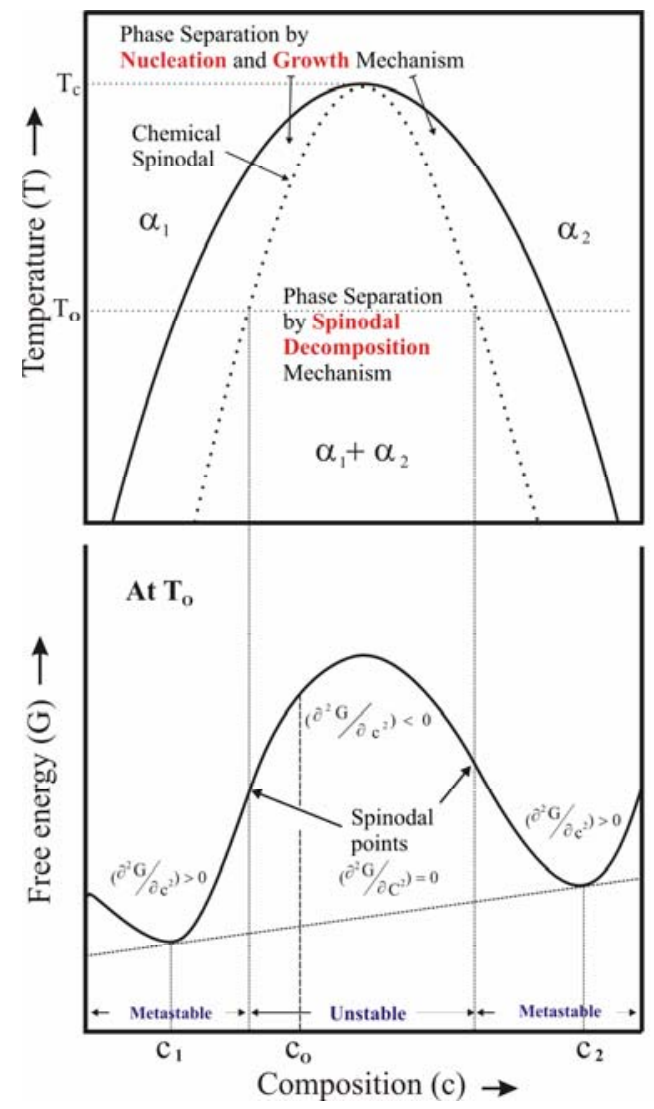

Fig. 1: (a) Hypothetical phase diagram of a binary system showing the miscibility gap and the region of chemical spinodal. (b) Variation of the free energy $(\mathrm{G})$ with composition $(\mathrm{C})$ at temperature $T_{0}$ in the system shown in (a). The spinodal points are defined by $\partial^{2} \mathrm{G} / \partial \mathrm{c}^{2}=$ 0. Inside the spinodal $\partial^{2} \mathrm{G} / \partial \mathrm{c}^{2}$ is negative (unstable region), and outside the spinodal $\partial^{2} \mathrm{G} / \partial \mathrm{c}^{2}$ is positive (metastable region).

\section{$\underline{\text { Experimental procedure }}$}

The U-6 $\mathrm{wt} \% \mathrm{Nb}(\mathrm{U}-6 \mathrm{Nb})$ alloy used for this investigation was wrought processed from vacuum arc refined (VAR) ingot at the BWXT/Bechtel Y-12 plant, Oak ridge, TN. Detailed information regarding the fabrication process can be found in Ref. [2]. Nb contents (in wt $\%$ ) analyzed from different locations of the ingot were 5.79 (bottom edge), 5.97 (top edge), 6.03 (bottom center), and 6.10 (Top center). Five 
rod-shape samples of $3 \mathrm{~mm}$ in diameter were machined from a wrought-processed $38 \mathrm{~mm}$ thick plate. Each of these five samples was then encapsulated in a $\mathrm{Cu}$ tube and was solution treated at $800^{\circ} \mathrm{C}$ for 4 hours followed by water quench. One of the water-quenched samples was examined and characterized under as water-quenched condition (designated as WQ). The remaining four of the water-quenched samples were artificially aged at $200^{\circ} \mathrm{C}$ for 2 hours (designated as $2 \mathrm{~h}$ ), 4 hours (4h), 8 hours ( $8 \mathrm{~h}$ ), and 16 hours (16h). The naturally aged specimens were machined directly from a $38 \mathrm{~mm}$ thick plate. Rodshaped specimens of $3 \mathrm{~mm}$ in diameter were prepared for microstructure analysis and artificial aging experiment. The WQ-U6Nb alloy was obtained by solution treating the alloy at $800^{\circ} \mathrm{C}$ for 4 hours followed by water quenching. It was then followed by artificially aging carried out in a vacuum furnace at $200^{\circ} \mathrm{C}$. The naturally aged (NA) samples used for this investigation were prepared from 15 to 18 -year old mechanical parts. The NA alloy samples were subsequently aged at $200^{\circ} \mathrm{C}$ for $2 \mathrm{~h}, 24 \mathrm{~h}, 96 \mathrm{~h}, 200$ h, $240 \mathrm{~h}$, and $288 \mathrm{~h}$ in a vacuum furnace. Microhardness measurements were performed on all these samples using a Vickers-hardness tester. The applied load was $50 \mathrm{~g}$ and the time duration is 35 seconds for each test. To obtain a statistically significant value, more than six tests were conducted for each measurement. Tensile tests were performed in air at room temperature with an INSTRON survohydraulic testing machine. Dog-bone shape specimens with gauge dimensions of $6.4 \times 1.0 \times 19 \mathrm{~mm}$ were used for tensile tests. The amount of strain was measured with a clip-on extensometer. All the tests were employed a constant strain-rate of $1 \times 10^{-3} \mathrm{sec}^{-1}$ and were terminated when the specimen fractured in the gauge section. The microstructures of WQ alloy, WQ plus artificial aging (AA), WQ plus natural aging (NA), and WQ plus NA and AA (specified as accelerative aging hereafter) conditions were examined using an optical microscope and a JEOL-200CX transmission electron microscope (TEM). TEM foils were machined from the rod-shape samples, and the final thinning of the foils was prepared by twin-jet electropolishing in a solution of 45 vol.\% methanol, 45 vol.\% butyl alcohol, and 10 vol.\% nitric acid at $50 \mathrm{~V}$ and $-20^{\circ} \mathrm{C}$. 


\section{$\underline{\text { Results }}$}

\section{Artificial aging of as-WQ alloy at $200^{\circ} \mathrm{C}$}

The values of microhardness (in HV unit) measured from WQ-U6Nb samples artificially aged at $200^{\circ} \mathrm{C}$ for different aging durations are shown in Fig. 2, in which the values of microhardness measured from the accelerative aging of NA samples at $200^{\circ} \mathrm{C}$ are also shown for a comparison. It can be clearly seen that age hardening is observed from both WQ and NA samples subjected to aging treatment at $200^{\circ} \mathrm{C}$. However, there are significantly different aging phenomena revealed between the two in terms of hardening rate, peak hardness, and time to reach peak hardness. The microhardness increases to a much greater value, and the aging time required to reach hardness peak is much longer for the accelerative aging of NA sample. These different aging phenomena can be attributed to the involvement of different aging mechanisms in WQ and NA samples, which will be proposed and discussed below.

The WQ alloy sample has an initial microhardness of 190; it increases to 210 after aging for 2 hours. The microhardness continually increases to 237 for 4 hours and 254.8 for 8 hours. Within the first 8 hours of aging treatment, the hardening continues but with a decreasing trend. Further aging causes softening after the microhardness reaches a maximum value at 8 hours, and the microhardness reduces to 237 for 16 hours. This result is in agreement with the microhardness changes in artificially aged WQU6 $\mathrm{Nb}$ previously reported in [7]. Figures $3 \mathrm{a}-3 \mathrm{c}$ are low-magnification TEM images, which reveal that the change of morphology in artificially aged WQ samples such as the coarsening of twin domains is barely noticeable. Nevertheless, high-magnification TEM images shown in Figs. 4a - 4d, which were obtained from $2 \mathrm{~h}, 4 \mathrm{~h}, 8 \mathrm{~h}$, and $16 \mathrm{~h}$ aged samples, reveal the formation of a nanoscale modulated structure within the aged samples. The modulated structure, which is presumably resulted from a fluctuation wave of $\mathrm{Nb}$ content, is found to prevalently propagate in the elastically softest [001] direction. In addition, the modulated structure with a wavelength of $\sim 3 \mathrm{~nm}$, which causes the appearance of satellite spots adjacent to the Bragg diffractions, can also be found in the diffraction patterns shown in Figs. 4a - 
4c. In addition to the prevalent modulation waves, as shown in Figs. 5a and 5b, modulation waves propagating in the [ $\overline{1} 12]$ and [1 $\overline{1} 2]$ directions and modulation waves with a wavelength of $\sim 1.5 \mathrm{~nm}$ were also observed from local regions within the $4 \mathrm{~h}$ sample. However, it is worthy to note that these nonprevalent waves of modulation are considered to be energetically unfavorable and would eventually decay.

The modulated structure appeared as dark/bright striations in TEM images and satellite spots in electron diffraction patterns are two unique features that evidence the occurrence of spinodal decomposition. It is accordingly suggested that, based on the sharpness of striation contrast and the changes of microhardness, the modulated structure starts forming at 2 hours and becomes fully developed at 8 hours. After modulation is fully developed, further aging leads to the coarsening of the modulated structure as shown in Fig. 4d, in which the wavelength of modulated structure observed at a local region in $16 \mathrm{~h}$ sample increases to $\sim 50 \mathrm{~nm}$. The microhardness significantly decreases when coarsening of the modulated structure takes place.

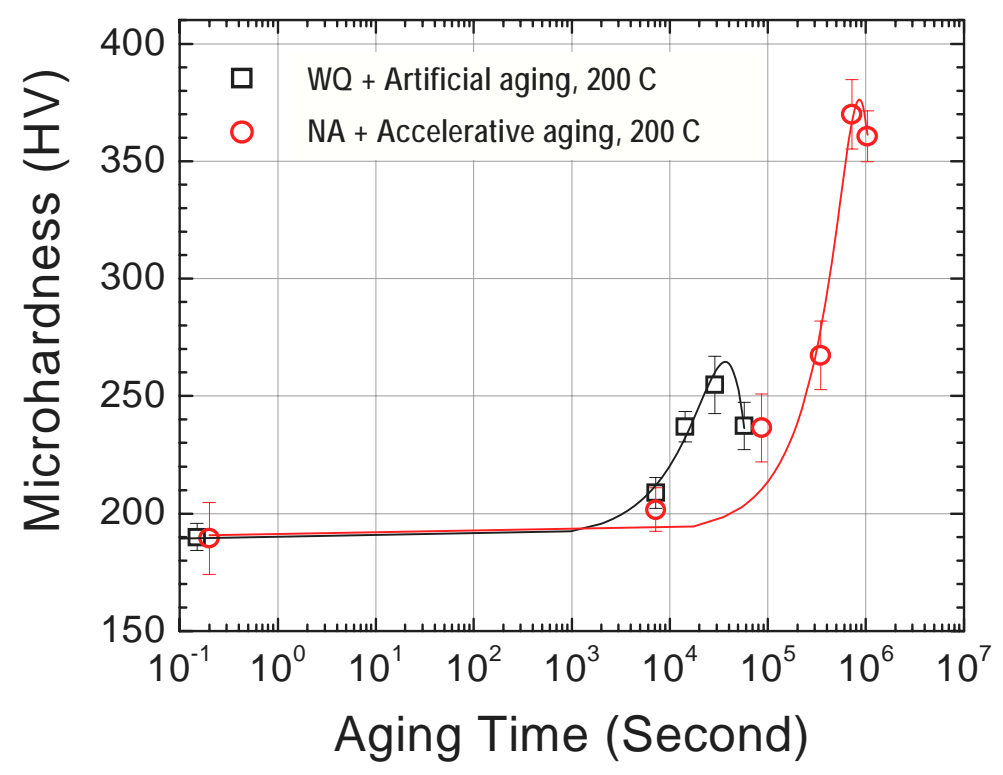

Fig. 2: The changing of microhardness during the aging treatment of WQ-U6Nb alloy at $200^{\circ} \mathrm{C}$ for up to 16 hours and during the aging treatment of NA alloy at $200^{\circ} \mathrm{C}$ for up to 288 hours. 


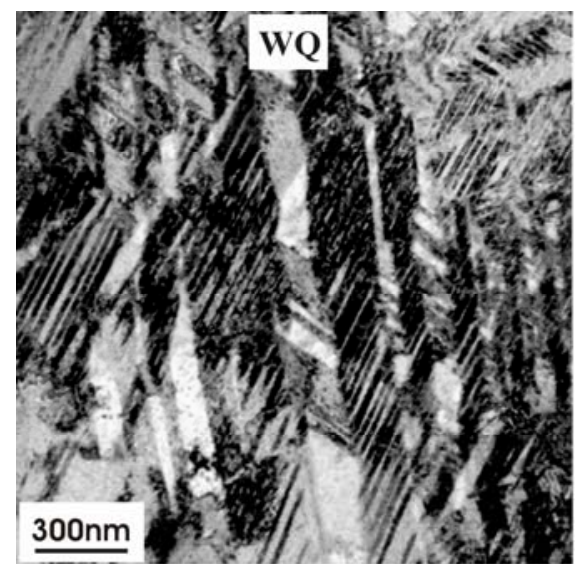

(a)

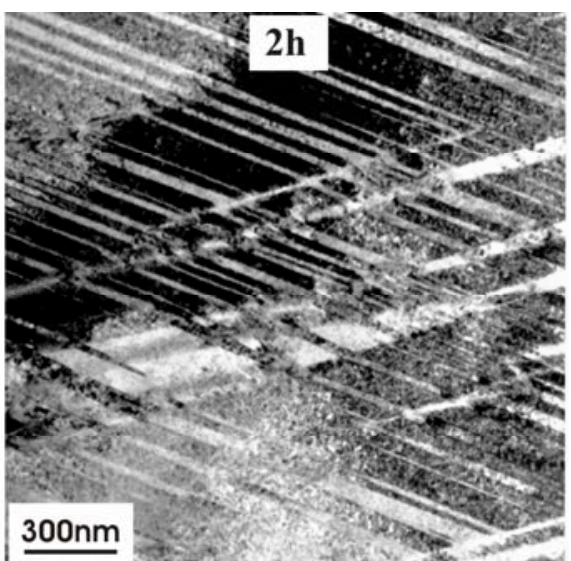

(b)

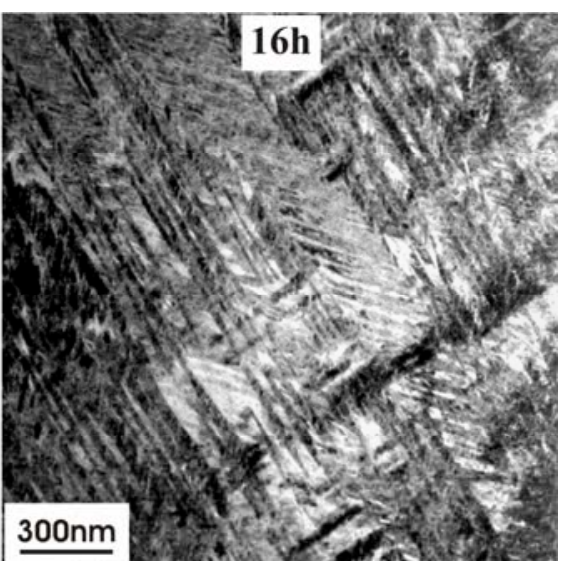

(c)

Fig. 3: Low-magnification TEM images showing (a) the microstructure of as water-quenched (WQ) U6Nb sample and (b, c) the microstructures of WQ samples after aging treatment at $200^{\circ} \mathrm{C}$ for 2 hours and 16 hours.
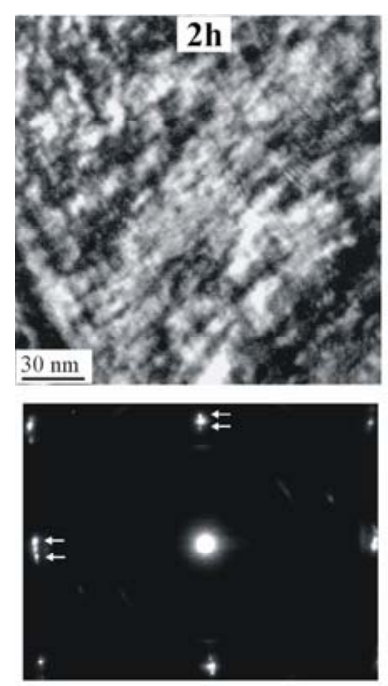

(a)

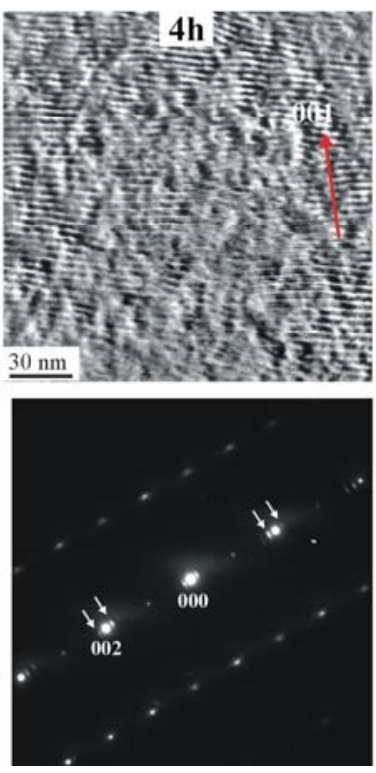

(b)

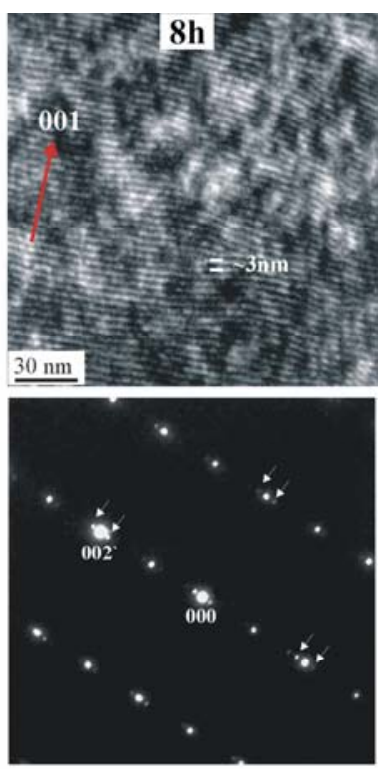

(c)

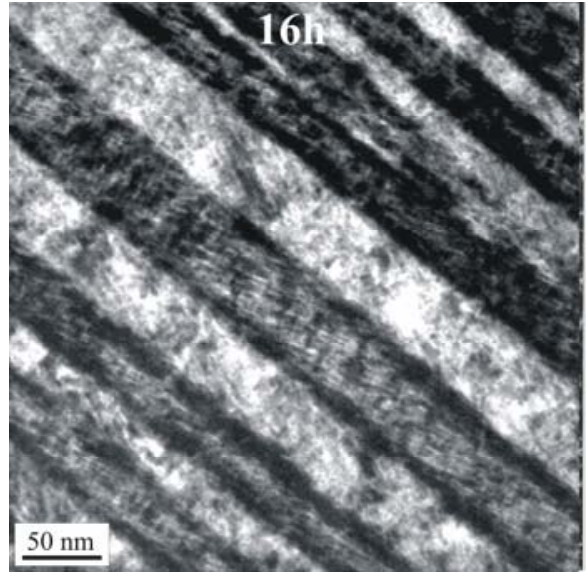

(d)

Fig. 4: TEM images and selected-area diffraction (SAD) patterns showing the formation of modulated structures within the $2 \mathrm{~h}, 4 \mathrm{~h}, 8 \mathrm{~h}$ and $16 \mathrm{~h}$ samples. The satellite (side) diffraction spots caused by the modulated structures are marked by arrows in selected-area diffraction patterns shown in (a), (b), and (c). Coarsening of the modulated structure observed from the local region of $16 \mathrm{~h}$ sample is shown in $(\mathrm{d})$. 

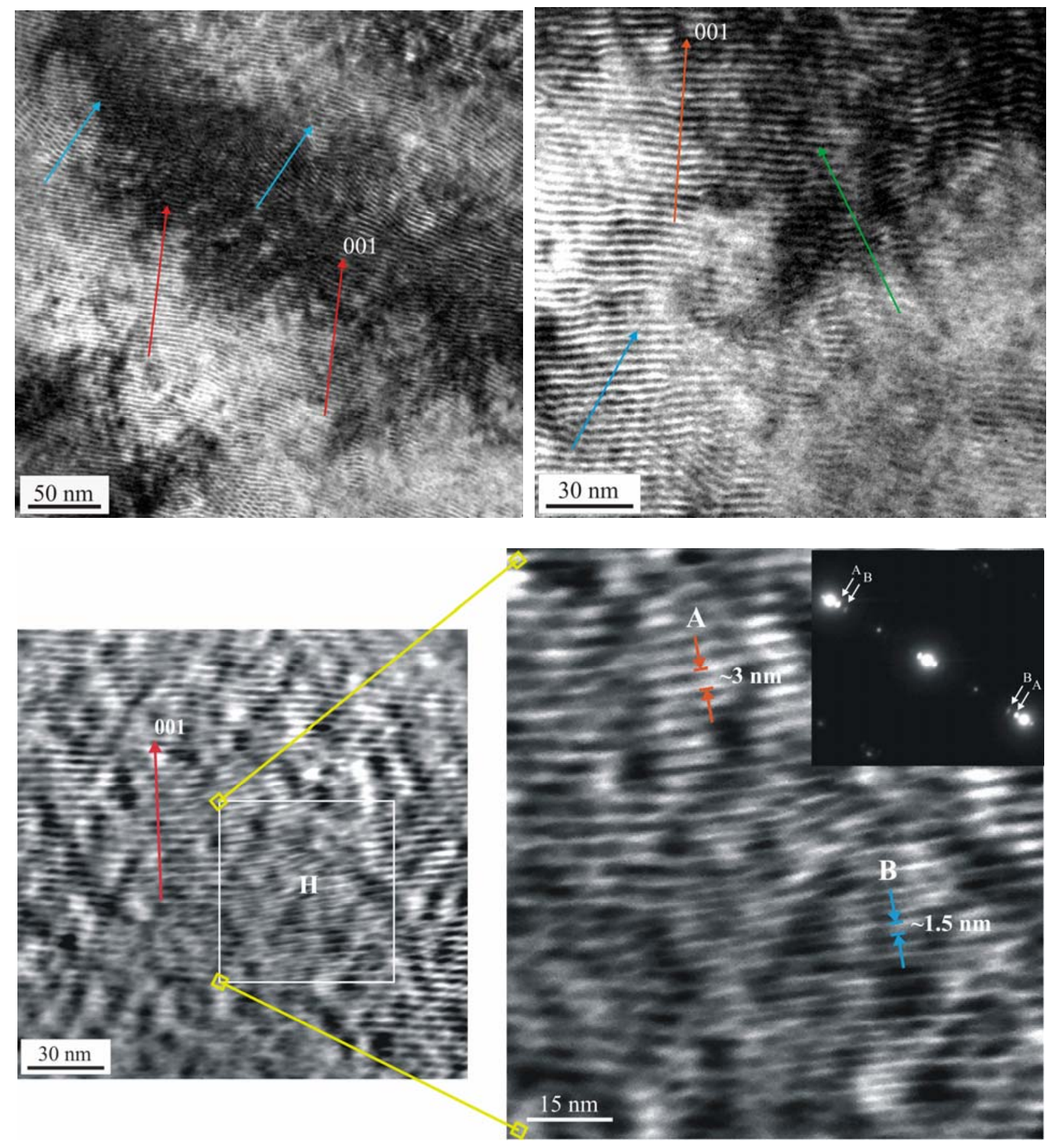

Fig. 5: (a) TEM images showing three different propagating directions of modulation waves: i.e., [001], [112] and [1 12 ], among which the [001] direction is the prevalent direction; (b) TEM images showing two different wavelengths of modulation waves: $\sim 1.5 \mathrm{~nm}$ and $\sim 3 \mathrm{~nm}$, and the prevalent wavelength is $\sim 3 \mathrm{~nm}$. Both (a) and (b) were observed in local regions of the $4 \mathrm{~h}$ sample. 


\section{Natural aging of WQ alloy at ambient temperatures}

Similar to artificially aged WQ samples, the change of morphological in the NA sample is barely noticeable in low-magnification TEM images. However, an interesting feature observed from the NA sample is the formation of swirl-shape antiphase domain boundaries (APBs) as shown in Figs. 6a and 6b. As will be demonstrated later that the contrast of antiphase domain boundary (also known as $\pi$ boundary) is visible when the phase angle $\alpha=2 \pi \mathbf{g} \cdot \mathbf{P}=\pi$ and is invisible when $\alpha=2 \pi$ (where $\mathbf{g}$ is the reflection vector for imaging, and $\mathbf{P}$ is the displacement vector of APB) [16]. The observation of APBs reveals the occurrence of an order-disorder transformation, which results in the formation of partially ordered phase domains within the NA alloy. In essence, the partially ordered phase has the same crystal structure as that of the disordered $\alpha^{\prime \prime}$ phase, except that it takes up a superlattice arrangement due to the periodic occupation of lattice sites by specific atom species. The partially ordered phase, designated as $\alpha_{\mathrm{po}}$, is accordingly proposed here, and its crystal structure can be verified by a comparison between observed and simulated diffraction patterns demonstrated below.

Figure 7 illustrates two possible schemes of the disorder-order transformation occurred in the $\alpha^{\prime \prime}$ disordered solid solution with a mean concentration, i.e., $\mathrm{c}_{\mathrm{o}}=14 \mathrm{at} \% \mathrm{Nb}$, and the probability of random site occupancy on each lattice site by $\mathrm{U}$ and $\mathrm{Nb}$ is $86 \%$ and $14 \%$, respectively. For the ordering transformation of Scheme I as illustrated in Fig. 7a, the following three lattice sites (4 lattice sites/unit cell): $(0,5 / 6,1 / 2),(1 / 2,1 / 3,1 / 2)$, and $(1 / 2,1 / 2,0)$ are occupied solely by $U$ atoms, whereas the $(0,0,0)$ lattice site is randomly occupied by $\mathrm{U}$ and $\mathrm{Nb}$ atoms, and the probability of site occupancy by $\mathrm{U}$ and $\mathrm{Nb}$ are $44 \%$ and $56 \%$, respectively. For the ordering transformation of Scheme II as illustrated in Fig. 7b, the $(0,5 / 6,1 / 2)$ and $(1 / 2,1 / 3,1 / 2)$ lattice sites are occupied solely by $U$ atoms, whereas the $(0,0,0)$ and $(1 / 2,1 / 2,0)$ lattice sites are randomly occupied by $\mathrm{U}$ and $\mathrm{Nb}$ atoms, and the probability of site occupancy by $\mathrm{U}$ and $\mathrm{Nb}$ are $72 \%$ and $28 \%$, respectively. It is interesting to note that the Scheme II ordering transformation can also be considered to be a spinodal transformation in which the $\mathrm{Nb}$ content is 
fluctuated between 0 and 28 at.\% (i.e., $\mathrm{c}_{\mathrm{o}} \pm \delta \mathrm{c}$, and $\delta \mathrm{c}=14$ at.\%), and the wavelength $(\lambda)$ of composition fluctuation is equal to the lattice parameter of $\alpha^{\prime \prime}$ unit cell in the [001] direction, i.e. $\lambda=0.495 \mathrm{~nm}$, which is approximately an order of magnitude smaller than the wavelength of spinodal modulation observed within WQ-U6Nb aged at $200^{\circ} \mathrm{C}$. This type of ordering transformations resulted from the spinodal modulation with the wavelength of an interatomic spacing is called continuous ordering or continuous transformation as described in [17].

Diffraction patterns of the [110]-, [310]-, [312]-, and [100]-zone generated from an 18-year NA sample are shown in Figs. 8 and 9, in which the simulated diffraction patterns based on Schemes I and II transformations are also displayed. Since the simulated patterns for the [110]-, [310]-, and [312]-zone are no difference between Scheme I and II as shown in Fig. 8, they can not be used to verify the crystal structure. However, as shown in Fig. 9, the simulated patterns of the [001]-zone are different between Scheme I and II. Crystal structure of the partially ordered $\alpha_{\text {po }}$ phase is accordingly identified to be the type of Scheme II by the comparison of the observed and simulated [100]-zone diffraction patterns. A typical g.P image-contrast analysis for APBs in an 18-year NA sample is shown in Fig. 10, in which the APBs are visible using $00 \overline{1}$ and $0 \overline{2} \overline{1}$ reflections to image but become invisible when using $0 \overline{2} 0$ reflection to image.
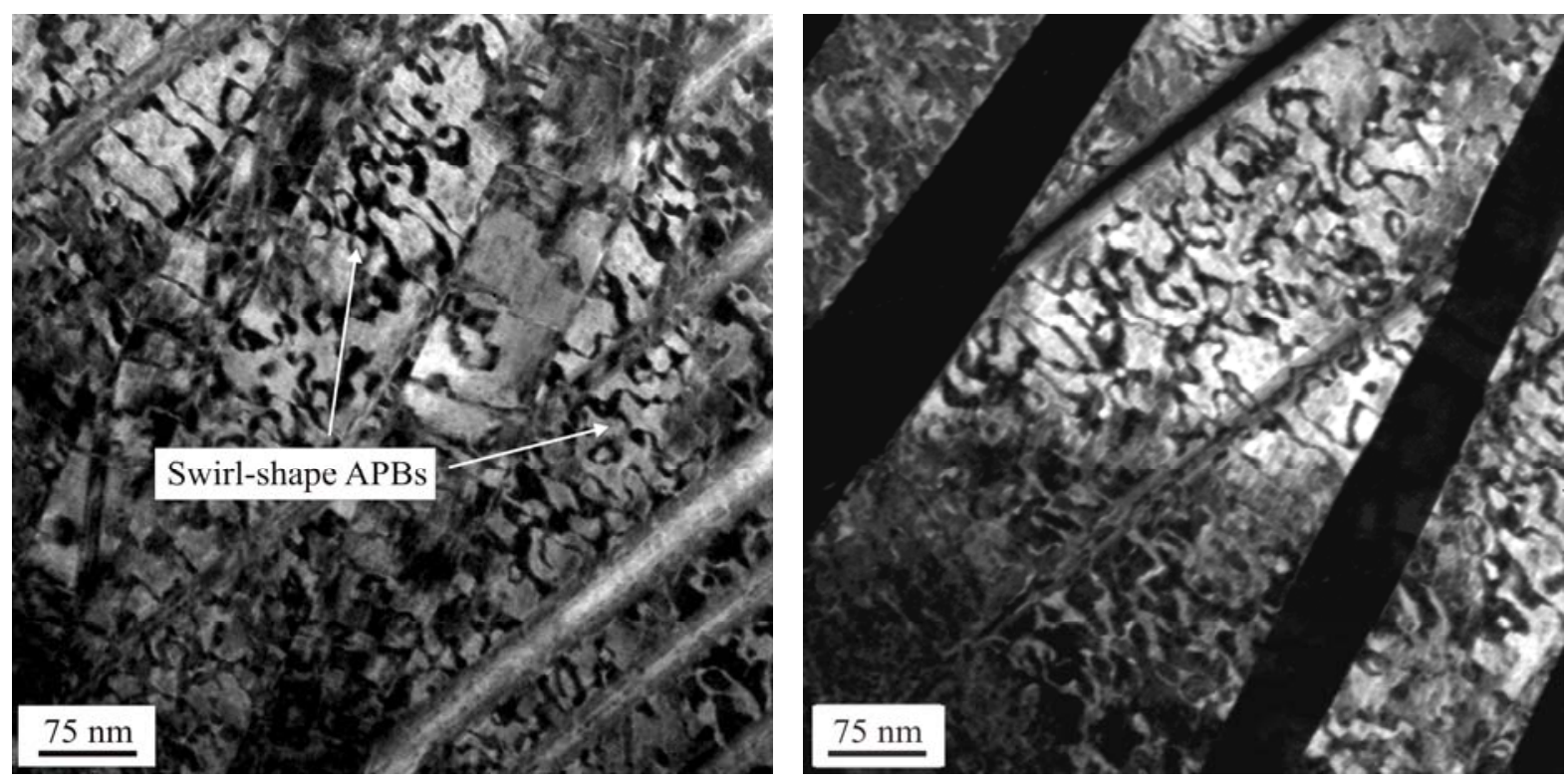
Fig. 6: Bright-field (a) and dark-field (b) TEM images reveal the formation of swirl-shape antiphase domain boundaries (APBs) within the NA sample.

(a)

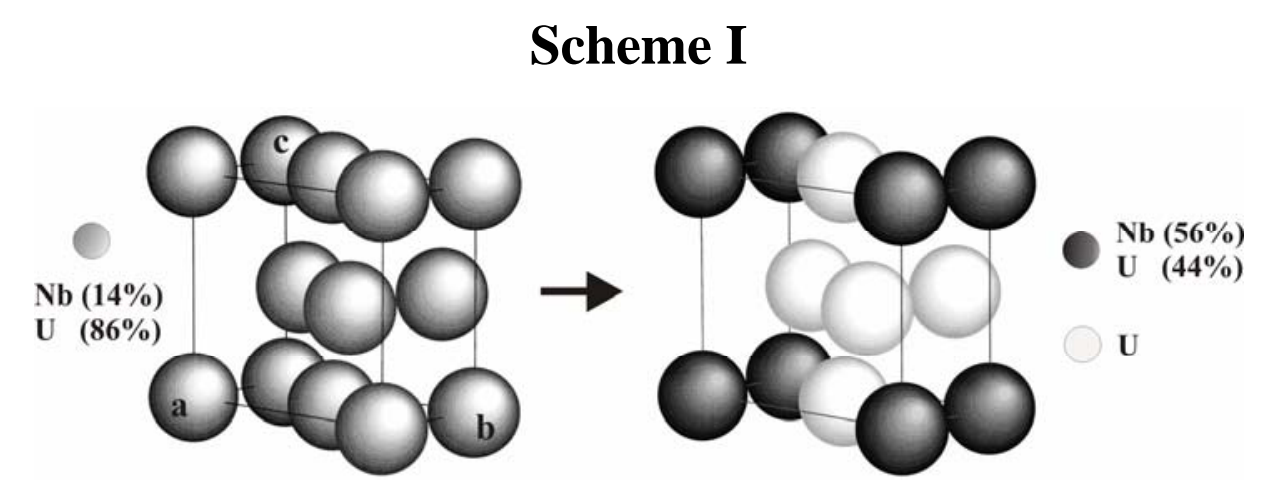

\section{Scheme II}

(b)
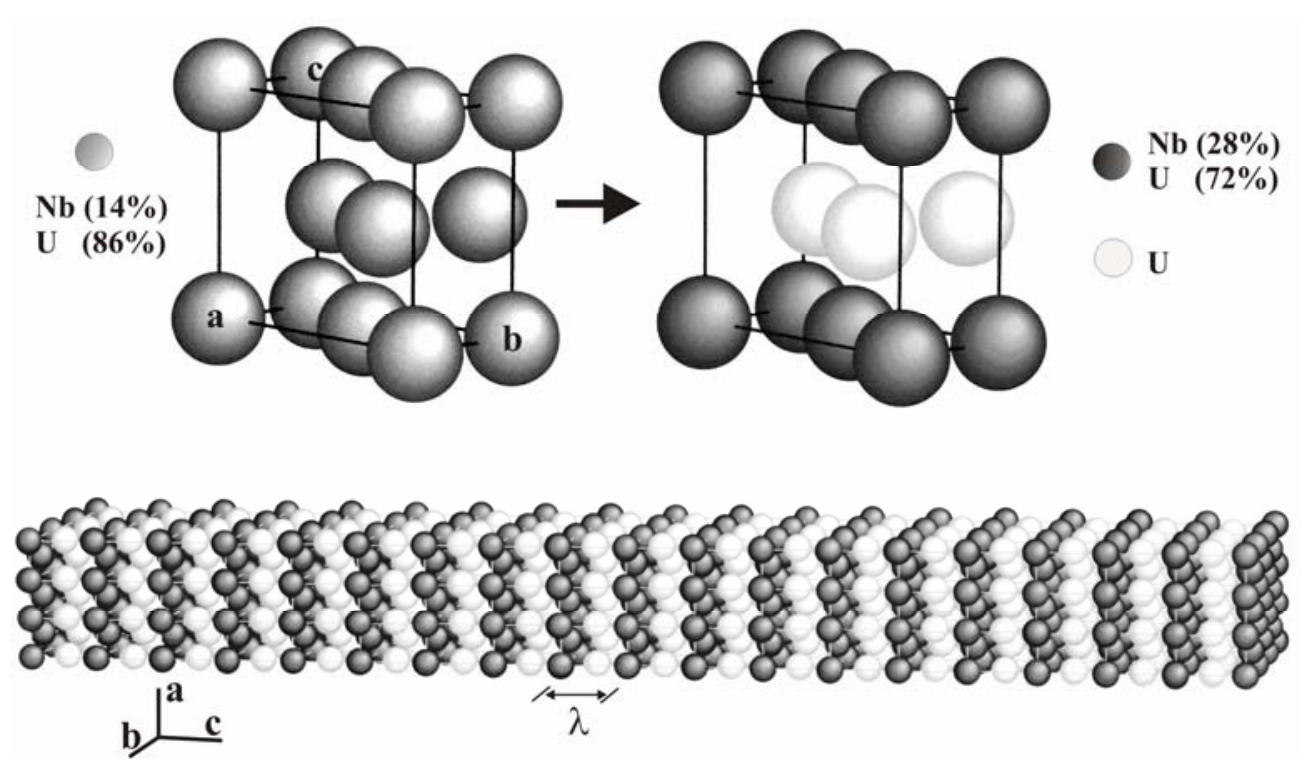

Fig. 7: Schematic illustrations showing two possible schemes proposed for the order-disorder transformation occurred in the U-14at.\% $\mathrm{Nb}(\mathrm{U}-6 \mathrm{wt} . \% \mathrm{Nb})$ alloy, in which two different partially ordered $\alpha_{\mathrm{po}}$ unit cells can be derived from (a) Scheme I. and (b) Scheme II ordering transformations. 


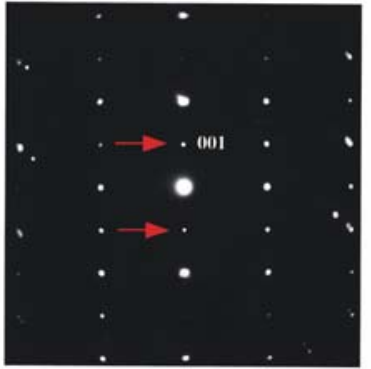

[110]

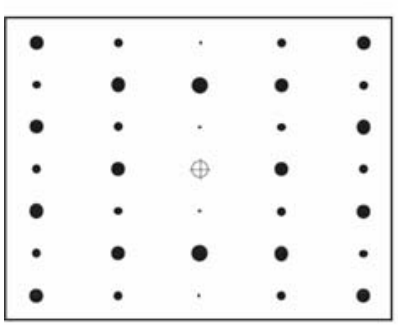

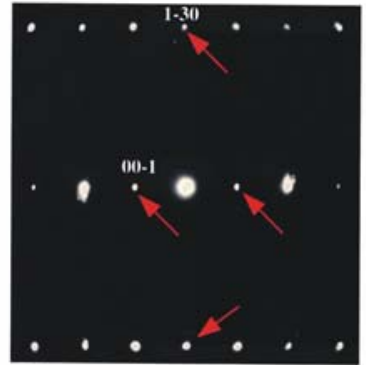

[310]

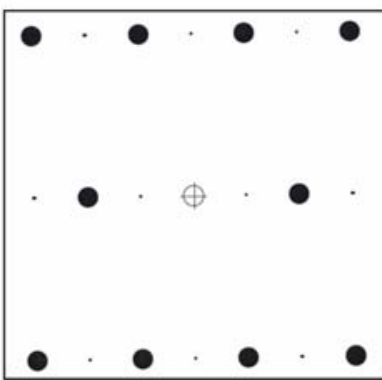

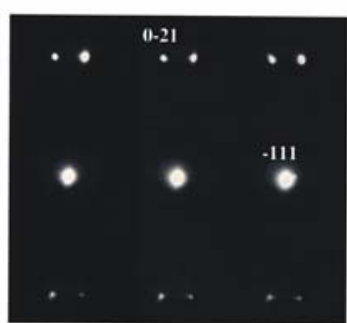

[312]

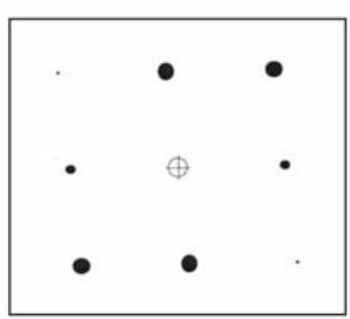

Fig. 8: The [110]-, [310]-, and [312]-zone diffraction patterns generated from the NA sample, in which the superlattice spots are arrowed (upper). Note that the [312]-zone diffraction pattern includes the diffraction spots generated from twin domains. The corresponding zone diffraction patterns simulated for the proposed partially ordered $\alpha_{\mathrm{po}}$ unit cell according to Schemes I and II ordering transformations are shown below.

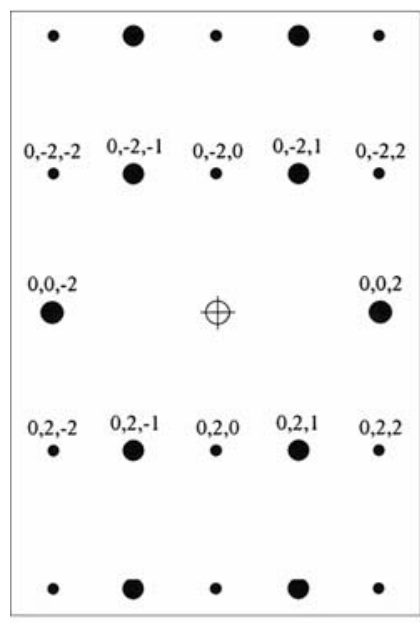

Disordered $\alpha^{\prime \prime}$

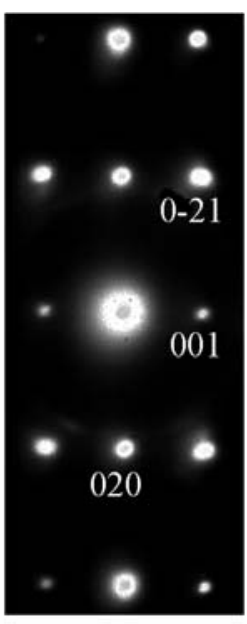

$[100]$

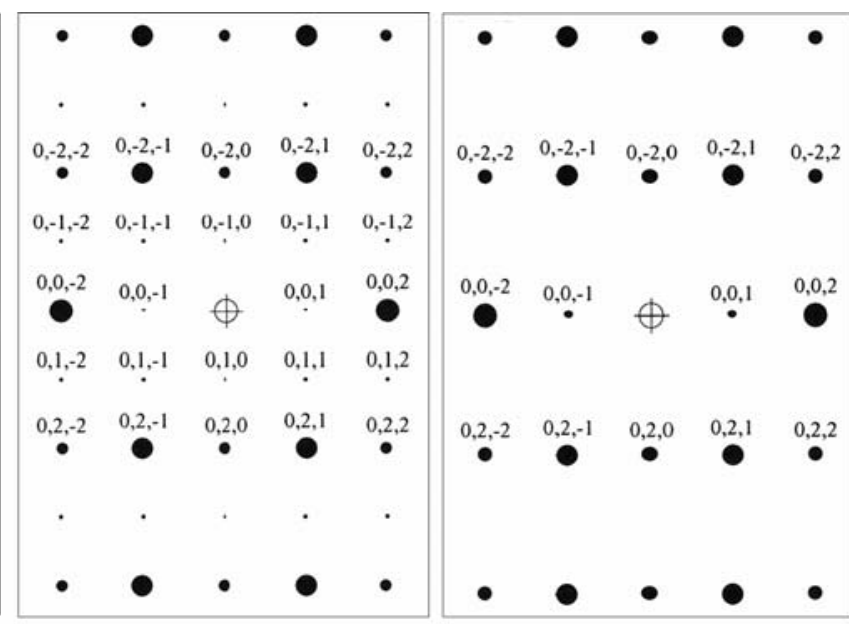

Scheme I

\section{Scheme II}

Fig. 9: The [100]-zone diffraction pattern generated from the NA sample displayed with simulated patterns based on scheme I and scheme II unit cells. Here, scheme II is more likely to be the one for the partially ordered $\alpha_{\mathrm{po}}$ phase according to the comparison between observed and simulated patterns. 


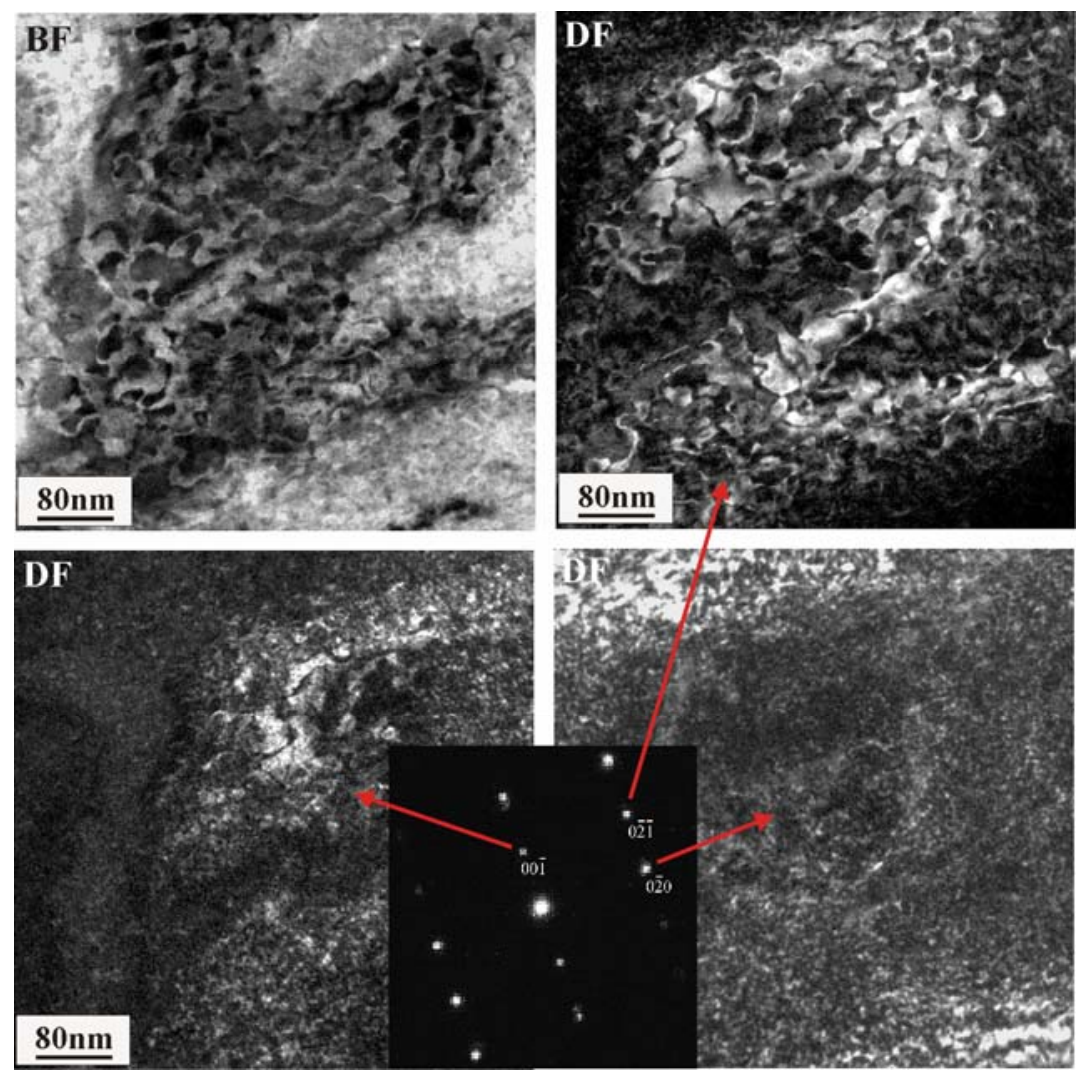

Fig. 10: BF and DF images of growth APBs in the NA alloy sample observed in the same area. The APBs are visible using $00 \overline{1}$ and $0 \overline{2} \overline{1}$ superlattice reflections to image but become invisible when using $0 \overline{2} 0$ fundamental reflection to image.

\section{Accelerative aging of NA alloy at $200{ }^{\circ} \mathrm{C}$}

To study how the long-term natural aging has affected the aging mechanisms, an accelerative aging experiment was conducted to NA alloy samples at $200^{\circ} \mathrm{C}$. The term "accelerative aging" is used here simply because the subsequent aging treatment at elevated temperatures in fact accelerates the on-going aging reaction, i.e., order-disorder transformation, in the NA samples. The changing of microhardness with increasing aging time is shown previously in Fig. 2. Notice that the NA sample has an initial microhardness 189.4, which is not much different to that of WQ-U6Nb alloy, which suggests that natural aging of WQ alloy over the past 15 to 18 years does not cause a significant change in the mechanical property. The microhardness of the NA alloy slightly increases to 202.6 after aging for 2 hours, and it continuously increases to 236.5 for 24 hours and 267.3 for 96 hours; it finally reaches the 
peak hardness of 374 for 240 hours that is much longer than the aging time (10 hours) required to reach the peak hardness of 265 for the artificial aging of WQ-U6Nb at $200^{\circ} \mathrm{C}$. Figure 11 shows the change of tensile stress/strain response and ductility of the NA alloy accelerative-aging at $200^{\circ} \mathrm{C}$, which reveals that the aging leads to not only age hardening but also ductility embrittlement. Here the ductility of the aged NA alloy reduces from $\sim 30 \%$ to $\sim 15 \%$ after aging at $200^{\circ} \mathrm{C}$ for 96 hours.

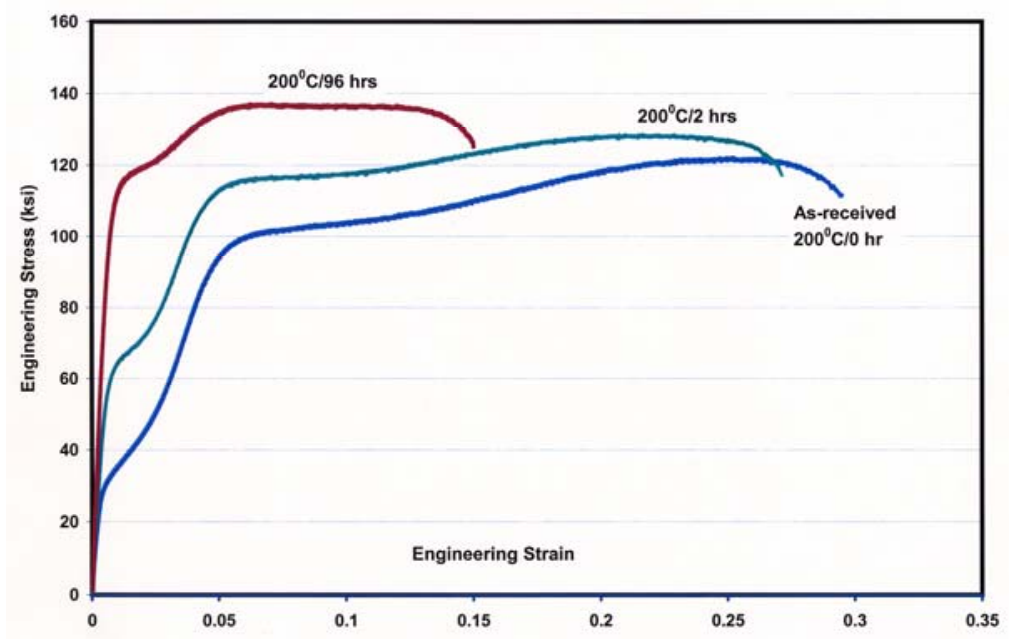

Figure 11: The changes of tensile stress-strain response and ductility of the NA alloy after accelerative aging at $200^{\circ} \mathrm{C}$ for 2 hours and 96 hours.

Results of optical metallography and TEM analyses for the microstructures evolution within the NA samples after accelerative aging at $200^{\circ} \mathrm{C}$ for different periods of time are shown in Figs. 12a $-12 \mathrm{f}$, which reveal clearly that phase decomposition of the $\alpha_{\mathrm{po}}$ phase has occurred in the NA samples by the nucleation and growth of precipitates within the samples, which is distinctly different from the spinodal decomposition of supersaturated $\alpha^{\prime \prime}$ phase occurred within the artificially aged WQ-U6Nb samples previously shown in Figs. $4 \mathrm{a}-4 \mathrm{~d}$. Figures $12 \mathrm{~b}-12 \mathrm{~d}$ are TEM images showing that the APBs formed with the NA sample are vanished after the accelerative aging, and the volume fraction and size of precipitates increase with aging time. Figure $12 \mathrm{e}-12 \mathrm{f}$ are optical micrographs showing the comparison of microstructures between samples aged at 2 hours and 288 hours. While no precipitate can be found in the $2 \mathrm{~h}$ sample, many coarsened precipitates of wedge-shape can be clearly seen in the $288 \mathrm{~h}$ sample. 
Results of TEM analysis for the crystal structures of an $\mathrm{Nb}$-enriched precipitate and an $\mathrm{Nb}$-depleted matrix phase are demonstrated in Figs. 13a - 13d. The crystal structures of both phases can be distinguished from those of supersaturated $\alpha^{\prime \prime}$ and $\alpha_{p o}$ phase according to the observed and simulated electron diffraction patterns. To identify crystal structures of the precipitate and matrix phase, two ordered orthorhombic unit cells, $\mathrm{U}_{3} \mathrm{Nb}(25 \mathrm{at} \% \mathrm{Nb})$ and $\mathrm{UNb}(50 \mathrm{at} \% \mathrm{Nb})$, and an $\mathrm{Nb}$-depleted orthorhombic $\alpha(\mathrm{U})$ unit cell are proposed and shown in Fig. 13b together with the simulated diffraction patterns corresponding to the proposed unit cells. The Nb-enriched precipitate is accordingly identified to be $\mathrm{U}_{3} \mathrm{Nb}(25 \mathrm{at} \% \mathrm{Nb})$, and the $\mathrm{Nb}$-depleted matrix phase is confirmed to be $\alpha(\mathrm{U})$ phase by comparing the observed and simulated diffraction patterns of [010]-, [001]-, and [110]-zone as shown in Figs. 13a13d. The $\mathrm{U}_{3} \mathrm{Nb}$ precipitate is designated hereafter as $\alpha_{0}$ phase, in which three $U$ atoms occupy the $(0,5 / 6,1 / 2),(1 / 2,1 / 3,1 / 2)$, and $(1 / 2,1 / 2,0)$ lattice sites, and one $\mathrm{Nb}$ atom occupy the $(0,0,0)$ lattice site.

(a)
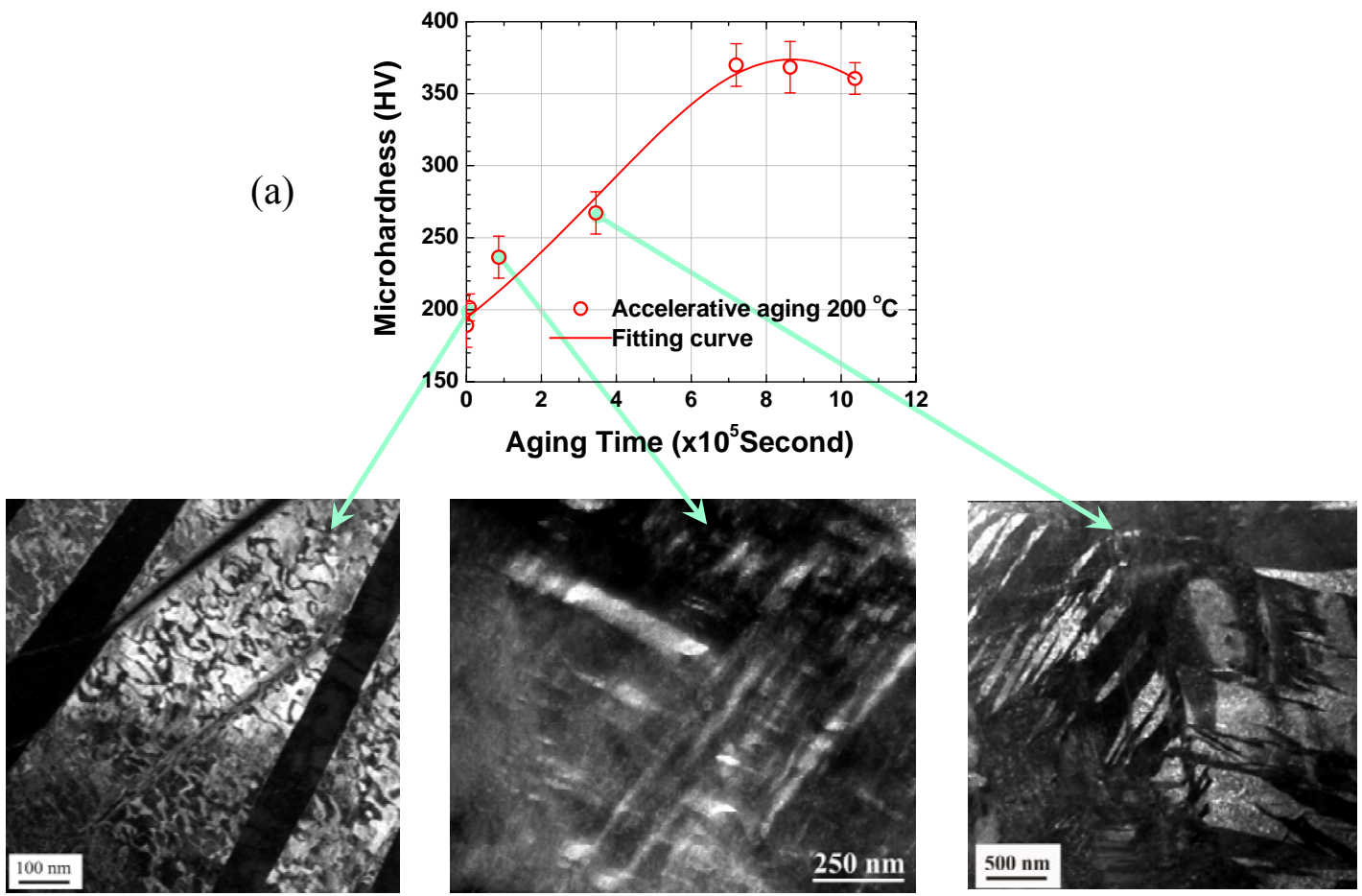

(b)

(c)

(d) 


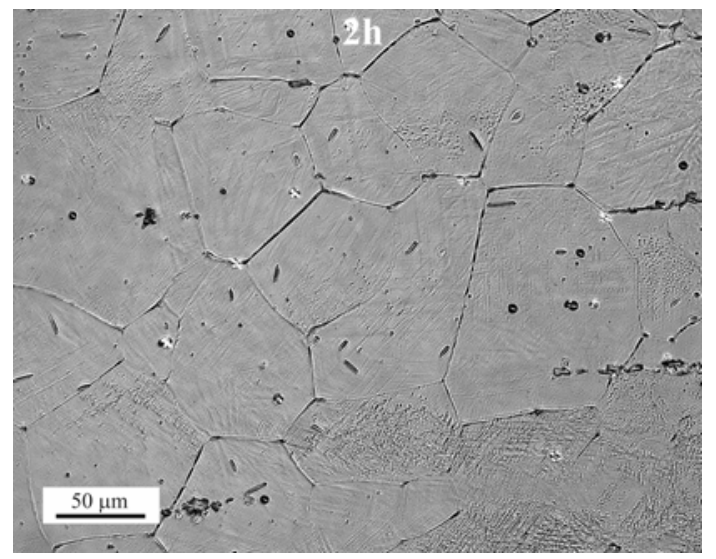

(e)

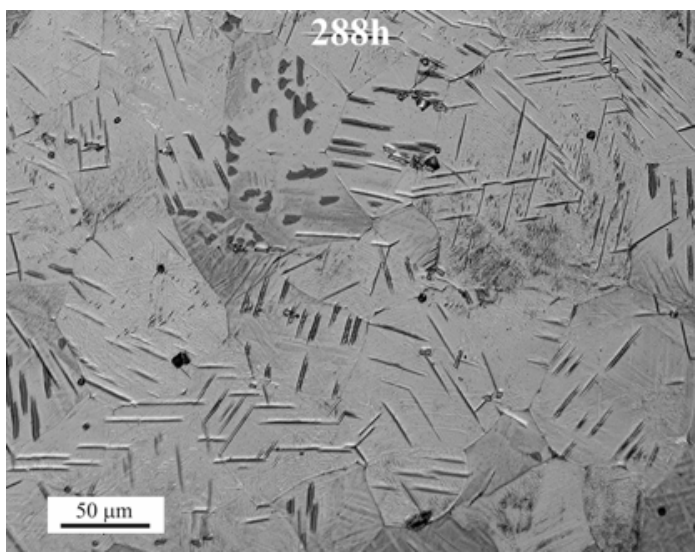

(f)

Fig. 12: (a) Precipitation hardening occurred during the accelerative aging of the NA alloy at $200^{\circ} \mathrm{C}$; TEM images showing (b) APBs in an NA alloy sample, (c) fine precipitates formed in an NA sample after aging for 24 hours, and (d) relatively higher volume fraction of precipitates formed in an NA sample after aging for 96 hours. The APBs observed in (a) are vanished after aging at $200^{\circ} \mathrm{C}(\mathrm{c}, \mathrm{d})$. Optical micrographs showing (e) the microstructure of NA sample after aging for 2 hours, and (f) the microstructure of NA sample after aging for 288 hours, in which many coarsened precipitates can be clearly seen.

(a)
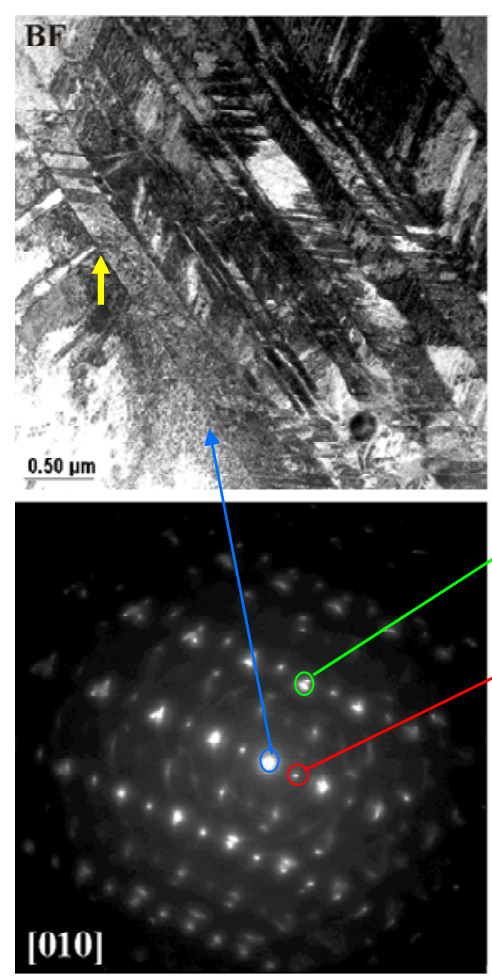
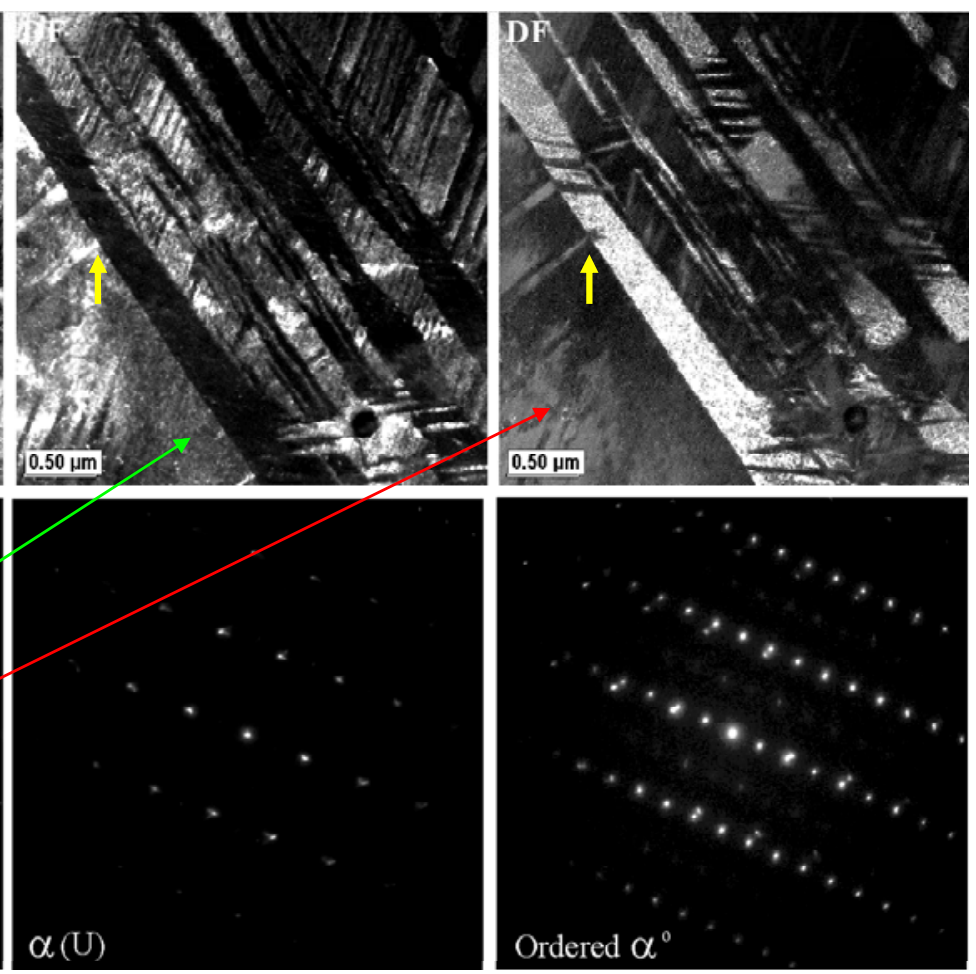
(b)
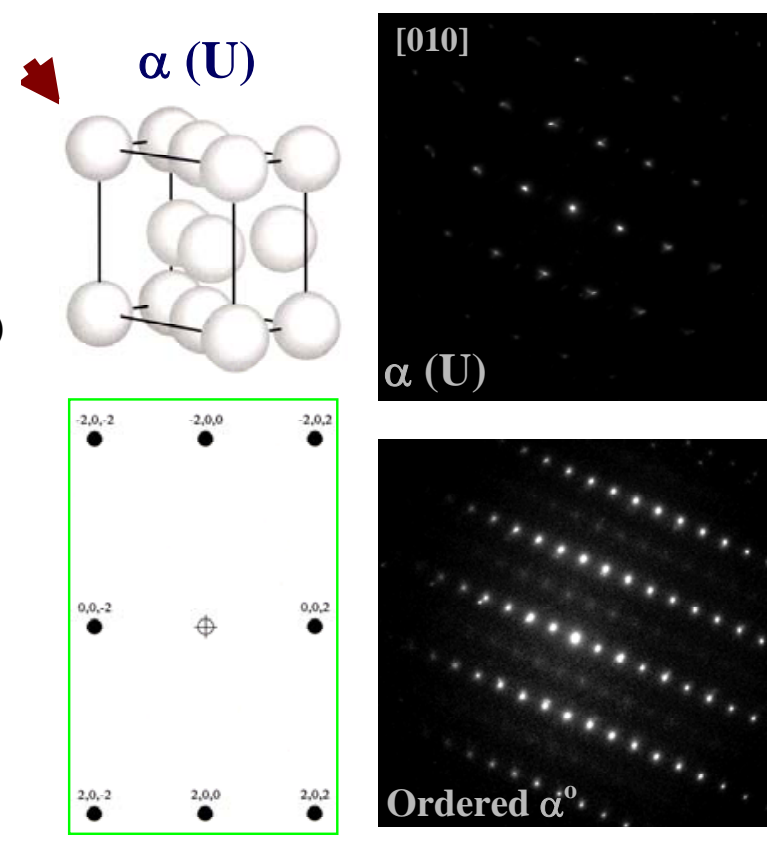

$\mathrm{U}_{3} \mathrm{Nb}$
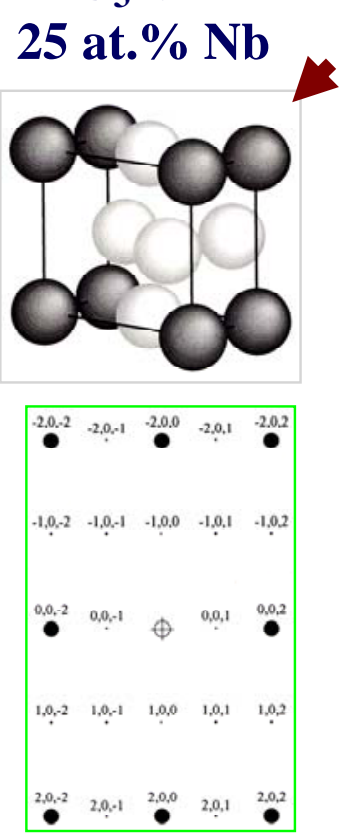

UNb

50 at. \% Nb

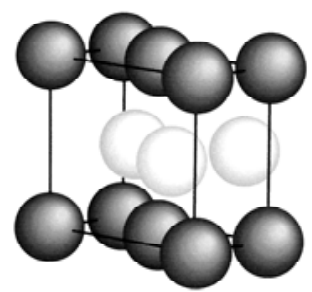

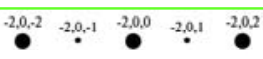

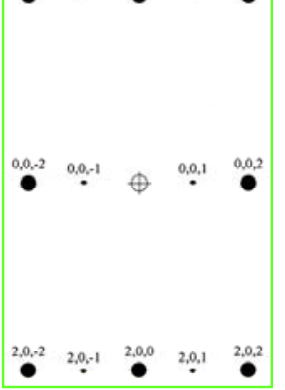

(c)
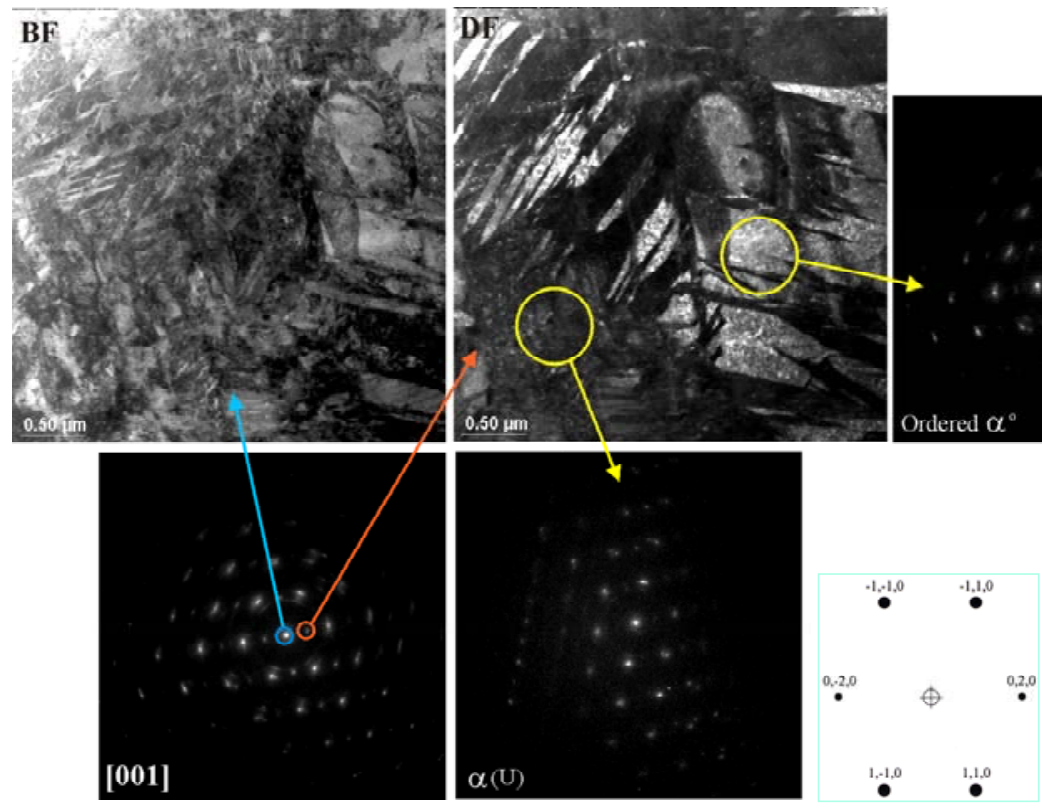

[001]

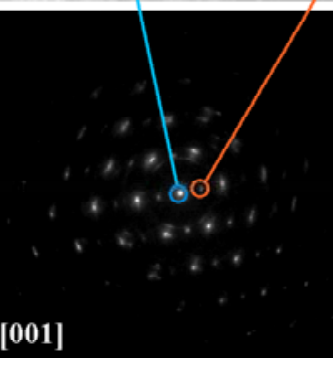

$0.50 \mathrm{~mm}$ 
(d)
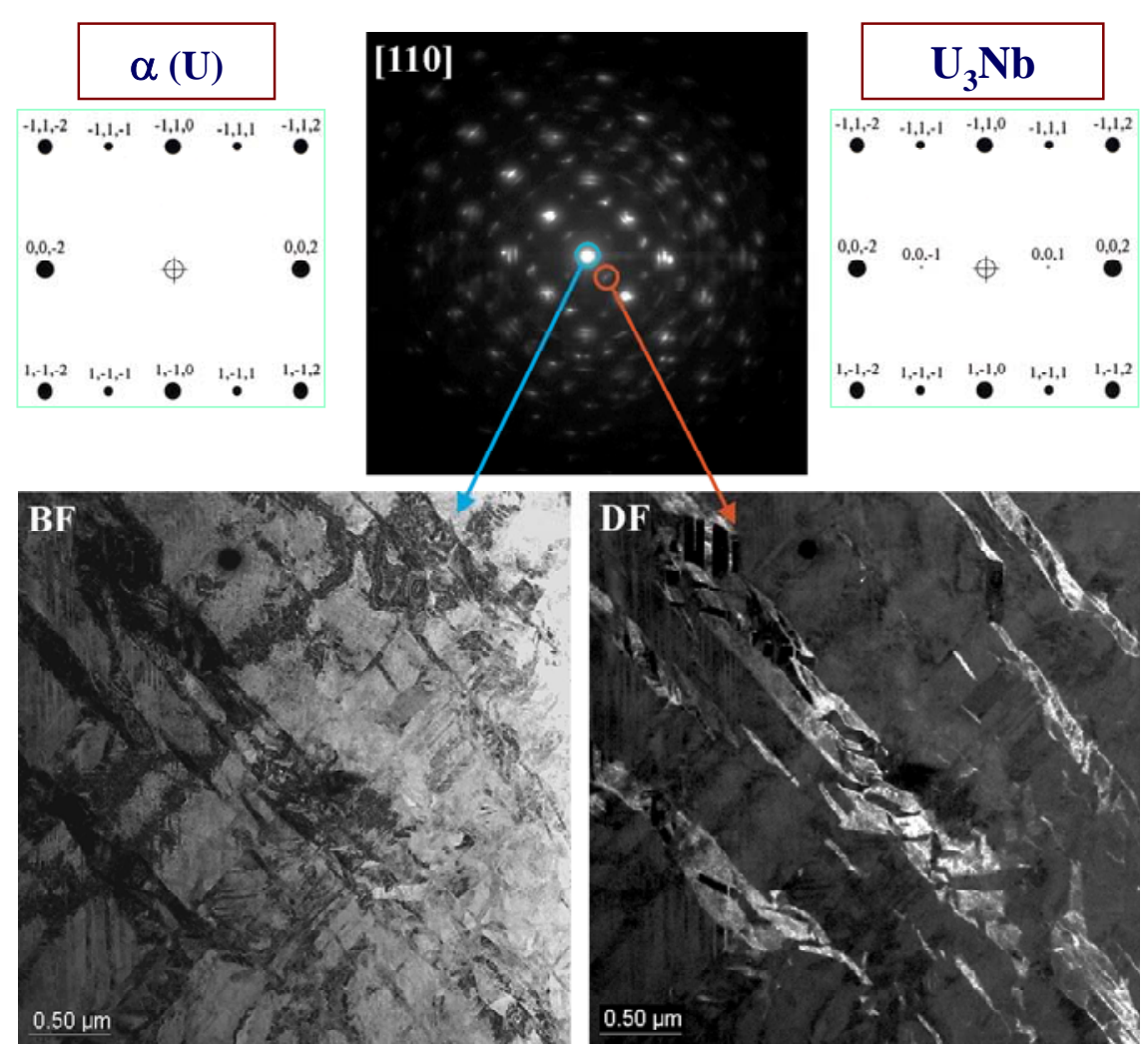

Fig. 13: The identification of $\mathrm{Nb}$-depleted $\alpha(\mathrm{U})$ phase and $\mathrm{Nb}$-enriched $\mathrm{U}_{3} \mathrm{Nb}$ ordered phase formed in the NA sample after accelerative aging for 96 hours at $200^{\circ} \mathrm{C}$. (a, b) TEM images of decomposed domains, proposed $\alpha(\mathrm{U}), \mathrm{U}_{3} \mathrm{Nb}$, and $\mathrm{UNb}$ unit cells, and both observed and simulated diffraction patterns of [010]-zone; (c) [010]-zone, and (d) [110]-zone.

\section{$\underline{\text { Discussion }}$}

\section{Low-temperature aging behavior of WQ-U6Nb}

It is shown in Fig. 1, while age hardening behavior occurs in both the artificial aging of WQ alloy and the accelerative aging of NA alloy at $200^{\circ} \mathrm{C}$. A much longer aging time is required to reach hardness peak for the NA alloy. In addition, the hardness peak reaches to a much greater value for the NA alloy. This discrepancy suggests that the natural aging has a significant influence on the aging behavior as well as the aging mechanism of $\mathrm{WQ}-\mathrm{U} 6 \mathrm{Nb}$ at low temperatures. Detailed TEM analyses were accordingly performed to depict the influence of natural aging on the phase stability and aging mechanism of the alloy. The results clearly reveal that while spinodal decomposition occurs in the 
artificial aging of the WQ alloy samples, order-disorder transformation and precipitation occur in the accelerative aging of the NA alloy samples. A modulated structure with a prevalent wavelength of $3 \mathrm{~nm}$ is developed along the [001] direction of the supersaturated $\alpha^{\prime \prime}$ solid solution at the early stages of aging treatment (as illustrated in Fig. 14), which results in solution hardening. The natural aging of WQ samples renders the formation of partially ordered $\alpha_{\mathrm{po}}$ solid solution through an order-disorder transformation, which results in the development of antiphase domain boundaries (APBs) that appear as swirl-shape features in TEM images (Fig. 6). Through the crystallographic simulation framework demonstrated in Figs. 7 - 9, it reveals that the $\alpha_{\mathrm{po}}$ solid solution resulting from the order-disorder transformation also contains a compositional modulation along the [001] direction. The wavelength of the modulation is in the order of an atomic size, i.e. $\lambda \approx 0.5 \mathrm{~nm}$ (as illustrated in Fig. 14), which is approximately an order of magnitude smaller than the wavelength of modulation occurred at $200^{\circ} \mathrm{C}$. This temperature-dependency of spinodal modulation, i.e. the wavelength decreases with a decreasing temperature, is in agreement with the prediction according to the phenomenological theory of spinodal decomposition [9 - 11].
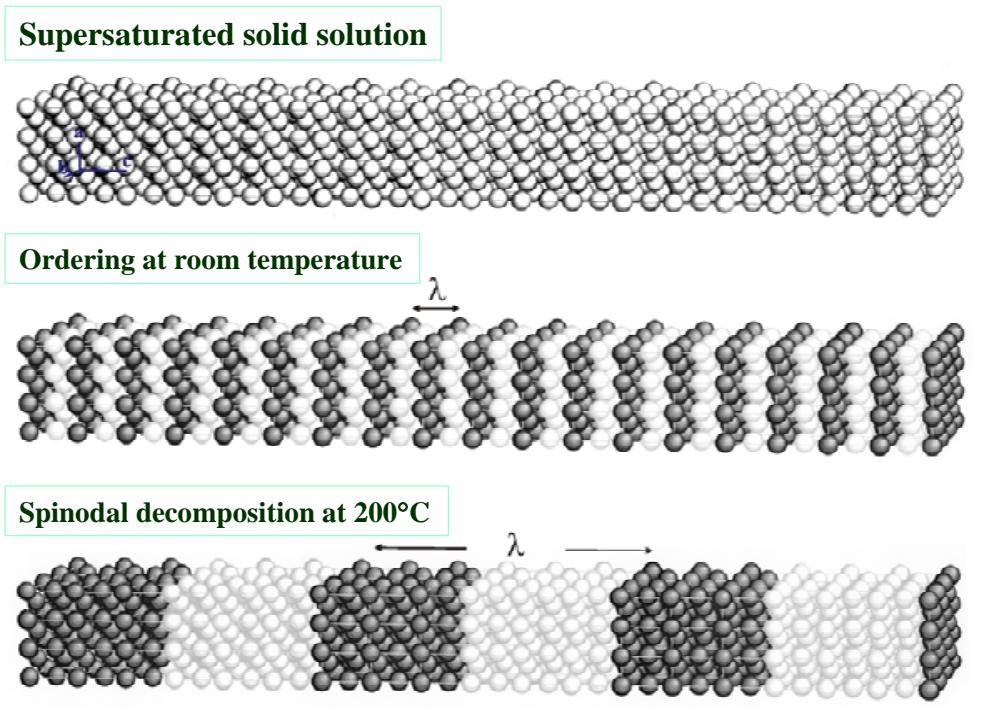

[001]

Fig. 14: Schematic illustrations showing the temperature dependency of the wavelength of composition modulation, in which the dark spheres represent the Nb-enriched atomic positions. 
If considering only the thermodynamic limit of spinodal decomposition, i.e., chemical spinodal, the change in Gibbs free energy per unit volume (V) of solid solution accompanying a composition fluctuation can be given as [11]:

$$
\frac{\Delta \mathrm{G}}{\mathrm{V}}=\frac{\pi \mathrm{B}^{2}}{4}\left[G^{\prime \prime}+2 \kappa \beta^{2}\right]
$$

The term $2 \kappa \beta^{2}$ accounts for interfacial-energy penalties due to concentration gradients, which is always positive, and $\kappa$ is a gradient energy constant, and the term increases with the decrease of wavelength $(\lambda$ $=2 \pi / \beta, \beta$ is the wave number). The supersaturated solution will decompose as a spinodal, when $\Delta \mathrm{G}<0$, i.e., $\left|\mathrm{G}^{\prime \prime}\right|>2 \kappa \beta^{2}$. The critical values of $\lambda\left(\lambda_{\mathrm{c}}\right)$ and $\beta\left(\beta_{\mathrm{c}}\right)$, respectively, at which $\Delta \mathrm{G}=0$ are:

$$
\lambda_{\mathrm{c}}=\left[-8 \pi^{2} \kappa / \mathrm{G}^{\prime \prime}\right]^{1 / 2} \text { and } \beta_{\mathrm{c}}=\left[-\mathrm{G}^{\prime \prime} / 2 \kappa\right]^{1 / 2} \text {. }
$$

At values of $\lambda<\lambda_{c}$ and $\beta>\beta_{c}$, the fluctuation will decay, and spinodal decomposition will not proceed. Since Gibbs free energy $(G)$ is a function of temperature $(T), G^{\prime \prime}$ can also be considered to be a function of temperature. If $\mathrm{T}_{\mathrm{o}}$ and $\mathrm{T}_{\mathrm{c}}$ are the aging and chemical spinodal temperatures, respectively, Taylor's expansion of $\mathrm{G}^{\prime \prime}$ with temperature leads to

$$
\mathrm{G}^{\prime \prime}+\left[\partial \mathrm{G}^{\prime \prime} / \partial \mathrm{T}\right]\left(\mathrm{T}_{\mathrm{o}}-\mathrm{T}_{\mathrm{c}}\right)+\ldots=0
$$

Noting that $\partial \mathrm{G}^{\prime \prime} / \partial \mathrm{T}=-\mathrm{s}^{\prime \prime}$ where $\mathrm{s}$ is the entropy per unit volume, and $\mathrm{s}^{\prime \prime}<0$ for an ideal solution. Thus, $\mathrm{G}^{\prime \prime}\left(\mathrm{T}_{\mathrm{o}}\right) \approx\left(\mathrm{T}_{\mathrm{o}}-\mathrm{T}_{\mathrm{c}}\right) \partial \mathrm{G}^{\prime \prime} / \partial \mathrm{T}=\left(\mathrm{T}_{\mathrm{c}}-\mathrm{T}_{\mathrm{o}}\right) \mathrm{s}^{\prime \prime}=\Delta \mathrm{Ts}^{\prime \prime}<0$, where $\Delta \mathrm{T}$ is the degree of undercooling. Therefore, $\left|G^{\prime \prime}(T)\right|$ is proportional to $\Delta T$. Since the wavelength of spinodal decomposition $(\lambda)$ is inversely proportional to $\left|G^{\prime \prime}(T)\right|$, the wavelength decreases when the degree of undercooling $(\Delta T)$ increases until the gradient energy term becomes significant. Accordingly, the formation of such an atomic-scale modulation at ambient temperatures can be attributed to a greater degree of undercooling $(\Delta \mathrm{T})$, which leads to a reduction of free energy through the exchange of nearest-neighbor atoms in the supersaturated solid solution. When the same species of atoms move to the same atomic planes, an atomic-scale modulation occurs, and the solution becomes chemically ordered. 
When aging at elevated temperatures, the degree of undercooling as well as the driving force for spinodal decomposition decreases, which leads to the formation of modulated structure with a longer wavelength. As a result, the supersaturated solution decomposes into two regions (or domains), i.e, $\mathrm{Nb}$ depleted and $\mathrm{Nb}$-enriched phases. Since there is a change of lattice parameters with the change of alloy composition, the influence of elastic distortion arising from the formation of coherent domains within the modulated structure becomes significant. The coherency strains thus affect the driving force and inhibit the spinodal reaction. In this case, i.e, coherent spinodal $[9,12]$, the change in Gibbs free energy $(\Delta \mathrm{G})$ per unit volume $(\mathrm{V})$ of solid solution accompanying a composition fluctuation becomes:

$$
\frac{\Delta \mathrm{G}}{\mathrm{V}}=\frac{\pi \mathrm{B}^{2}}{4}\left[G^{\prime \prime}+2 \kappa \beta^{2}+\mathrm{G}_{e l}\right]
$$

Where $G_{\text {el }}$ accounts for strain-energy penalties due to coherent interfaces, which is always positive, and is given by:

$$
\mathrm{G}_{\mathrm{el}}=1 / 2 \Sigma_{\mathrm{i}} \sigma_{\mathrm{i}} \varepsilon_{\mathrm{I}} \approx 2 \eta^{2} \mathrm{Y}
$$

Where $\sigma_{\mathrm{i}}$ and $\varepsilon_{\mathrm{i}}$ are coherent stress and strain, $\eta$ characterizes the change of linear dimensions of the lattice with the change of composition, and $\mathrm{Y}$ is the elastic constant which is dependent on the direction of composition modulation for anisotropic materials. Thus, for coherent spinodal, the critical value of $\beta$ $\left(\beta_{\mathrm{c}}\right)$, becomes:

$$
\beta_{\mathrm{c}}=\left[\left(-\mathrm{G}^{\prime \prime}+2 \eta^{2} \mathrm{Y}\right) / 2 \kappa\right]^{1 / 2}
$$

The value of $\beta_{\mathrm{c}}$ for coherent spinodal increases as a result of the influence of coherent strain, which leads to the reduction of driving force for the spinodal reaction. Accordingly, a preferential growth will occur along the direction that minimizes the coherent strain energy. The observation of modulated structure produced by a periodic composition waves preferentially propagating along the [001] direction reveals the formation of coherent spinodal in $\mathrm{U}-6 \mathrm{Nb}$ that is elastically anisotropic. 


\section{Proposed aging mechanisms and transformation pathways}

It has been demonstrated from the experimental results that the supersaturated solid solution in WQU6 $\mathrm{Nb}$ alloy is energetically unstable, it undergoes spinodal decomposition upon aging with the waves of modulation prevalently propagating in the [001] direction and the modulation wavelength is temperature dependent. For artificial aging of $\mathrm{WQ}-\mathrm{U} 6 \mathrm{Nb}$ alloy at $200^{\circ} \mathrm{C}$, the wavelength $(\lambda)$ of spinodal decomposition is $3 \mathrm{~nm}$; the solid solution decomposes into two phase domains with different $\mathrm{Nb}$ concentrations, and the transformation sequence is accordingly proposed to be supersaturated solid solution $\alpha^{\prime \prime}$-spinodal decomposition $\rightarrow \alpha^{\prime \prime}(\mathrm{Nb}-\mathrm{lean})+\alpha^{\prime \prime}(\mathrm{Nb}-\mathrm{rich})$. For the natural aging of WQ-U6Nb alloy samples at ambient temperatures as illustrated in Fig. 15, the wavelength of compositional modulation is in the order of an atomic size $(0.5 \mathrm{~nm})$, phase decomposition in fact does not occur, instead a partially ordered $\alpha_{\mathrm{po}}$ is formed as a result of the spinodal modulation of $\mathrm{Nb}$ within the unit cell, and the transformation sequence is proposed to be $\alpha^{\prime \prime}$-spinodal ordering $\rightarrow \alpha_{\text {po }}$, and the degree of long-range order [18], S, is 0.16 . Upon the accelerative aging at $200^{\circ} \mathrm{C}$, the degree of order of the solution could further increase to $\mathrm{S}=0.49$ when more $\mathrm{Nb}$ atoms occupy the $(0,0,0)$ lattice site of the partially ordered unit cell proposed previously for the Scheme I ordering transformation in Fig. 7. Phase decomposition eventually takes place by the precipitation of $\mathrm{U}_{3} \mathrm{Nb}(25 \mathrm{at} \% \mathrm{Nb})$ fully ordered phase $(\mathrm{S}=$ 1), which subsequently renders the formation of $\mathrm{Nb}$-depleted $\alpha(\mathrm{U})$ phase in the aged alloy, i.e., the reaction of $\alpha_{\mathrm{po}}$-phase decomposition $\rightarrow \alpha(\mathrm{U})+\alpha_{\mathrm{o}}\left(\mathrm{U}_{3} \mathrm{Nb}\right)$ that is governed by the nucleation and growth mechanism according to the results of TEM analysis shown in Figs. 12 and 13.

During the processes of phase decomposition in the supersaturated $\mathrm{U}-14 \mathrm{at} \% \mathrm{Nb}\left(\mathrm{c}_{\mathrm{o}}\right)$ solid solution at lower temperatures, unlike the decomposition reaction $\alpha^{\prime \prime} \rightarrow \alpha(\mathrm{U})+\gamma$ occurred above $400^{\circ} \mathrm{C}$, the crystal structure basically does not undergo significant alterations except the changes of lattice parameters resulting from the redistribution of $\mathrm{U}$ and $\mathrm{Nb}$ atoms through atomic diffusion. However, it is important to note that during the decomposition processes at ambient temperatures, a transition of 
decomposition mechanisms takes place from the spinodal ordering of supersaturated solution, i.e., $\alpha^{\prime \prime}\left(c_{o}\right.$ $=14 \mathrm{at} \% \mathrm{Nb}) \rightarrow \alpha_{\mathrm{po}}\left(\mathrm{c}_{\mathrm{o}}\right)$ to the nucleation and growth of $\mathrm{U}_{3} \mathrm{Nb}$ precipitates, i.e., $\alpha_{\mathrm{po}}\left(\mathrm{c}_{\mathrm{o}}\right) \rightarrow \alpha\left(\mathrm{U}, \mathrm{c}_{1}\right)+\alpha_{\mathrm{o}}$ $\left(\mathrm{U}_{3} \mathrm{Nb}, \mathrm{c}_{2}=25 \mathrm{at} \% \mathrm{Nb}\right)$. This suggests that there is a transition of thermodynamic state for the supersaturated solution system from an unstable state to a metastable state after the reaction of $\alpha^{\prime \prime}\left(c_{0}\right) \rightarrow$ $\alpha_{\mathrm{po}}\left(\mathrm{c}_{\mathrm{o}}\right)$ for order-disorder transition. In other words, the supersaturated solution system, which initially lies in the concave-down region of a Gibbs free energy-composition curve for a disordered solid solution, becomes lying in the concave-up region of a Gibbs free energy-composition curve for an ordered solid solution. This may be depicted and rationalized from the hypothetical phase and free energy-composition diagrams schematically illustrated in Fig. 16. Since the combined free energy of the decomposed solution is initially higher than the free energy of $\alpha_{\mathrm{po}}\left(\mathrm{c}_{\mathrm{o}}\right)$. As the reaction proceeds, the combined free energy will eventually be less than the initial free energy, and there is an energy barrier to be overcome during the decomposition process of $\alpha_{\mathrm{po}}\left(\mathrm{c}_{\mathrm{o}}\right) \rightarrow \alpha(\mathrm{U})+\alpha_{\mathrm{o}}\left(\mathrm{U}_{3} \mathrm{Nb}\right)$. The decomposition of such an ordered solution requires the nucleation-and-growth reaction.

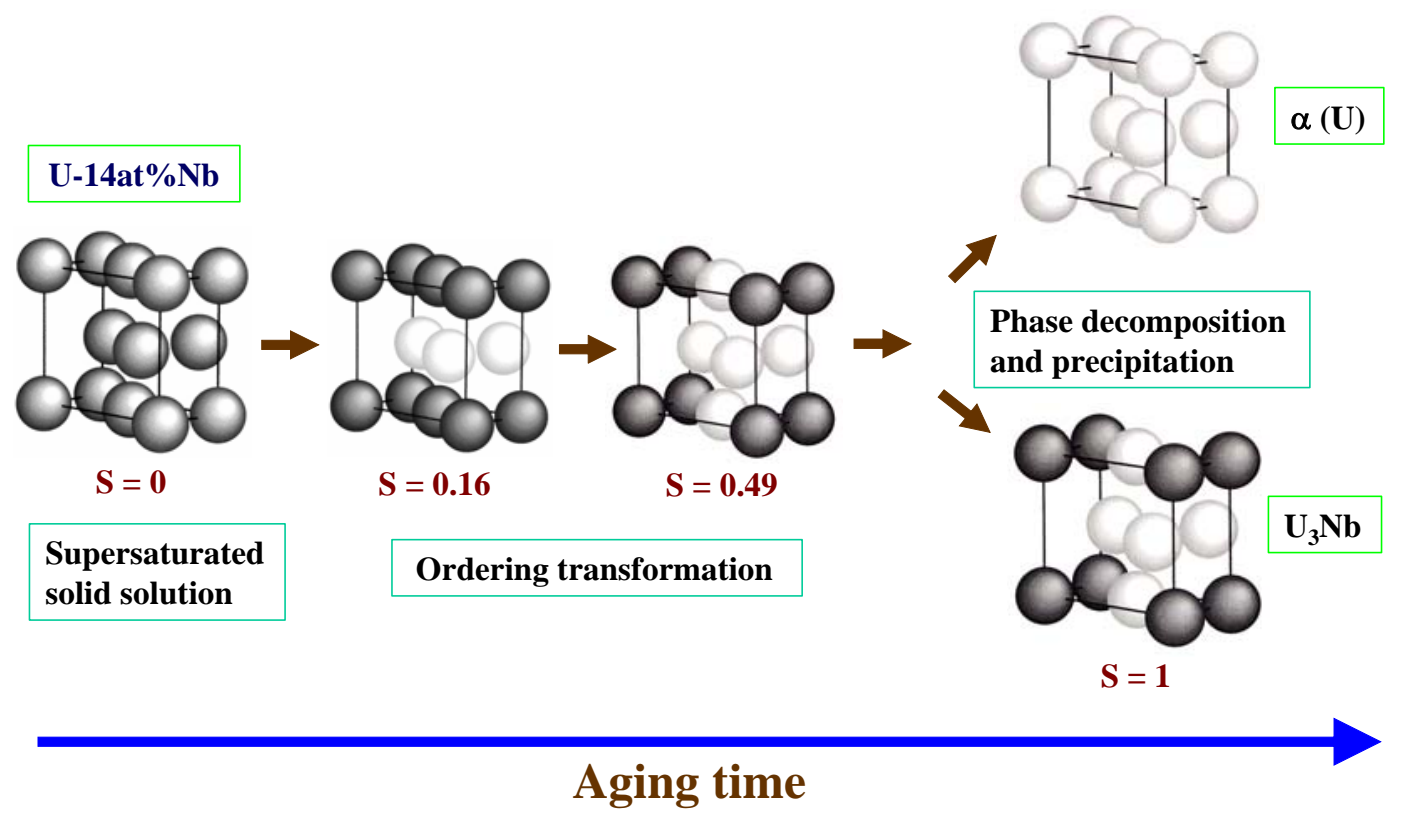

Fig. 15: Proposed phase transformation pathway for the aging of WQ-U6Nb at ambient temperatures. 


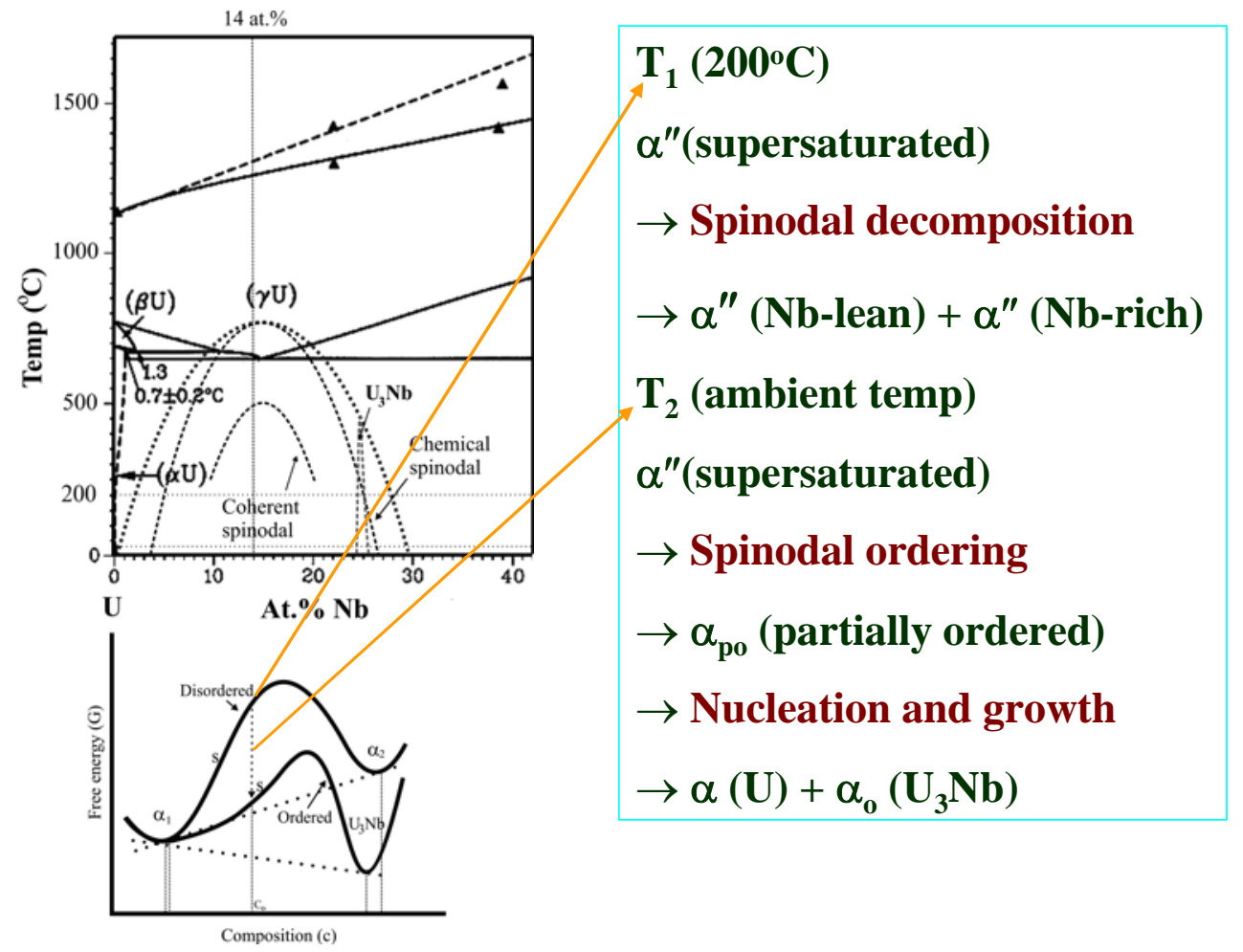

Fig. 16: Hypothetical free energy-composition diagram for disordered and ordered solid solution of binary U-Nb system.

\section{Conclusions}

Phase stability and aging mechanisms of a water-quenched (WQ) U-6wt\% $\mathrm{Nb}$ alloy artificial aging at $200^{\circ} \mathrm{C}$, natural aging at ambient temperatures for 15 to 18 years, and natural aging followed by accelerative aging at $200^{\circ} \mathrm{C}$ have been investigated using the techniques of microhardness testing, tensile testing, and TEM microstructural analysis. The results show that: 1) Age hardening phenomenon is observed from the artificially aged alloy samples, which can be rationalized by the occurrence of spinodal decomposition. A chemical modulation along the [001] direction with a wavelength of $\sim 3 \mathrm{~nm}$ is formed as a result of the spinodal decomposition. 2) An order-disorder transformation is found within the naturally aged alloy samples based upon the observation of antiphase boundaries (APBs), which can be rationalized by the occurrence of an atomic-scale spinodal ordering along the [001] direction. 3) New chemically ordered $\mathrm{U}_{3} \mathrm{Nb}$ phase is found to form within the naturally aged (NA) alloy samples after 
accelerative aging at $200^{\circ} \mathrm{C}$, which results in precipitation hardening and ductility embrittlement. Lowtemperature aging mechanisms and transformation pathways for WQ-U6Nb are proposed according to the results of TEM analysis. For artificial aging of WQ-U6Nb alloy samples at $200^{\circ} \mathrm{C}$, the transformation sequence is proposed to be $\alpha^{\prime \prime}$-spinodal decomposition $\rightarrow \alpha^{\prime \prime}$ (Nb-lean) $+\alpha^{\prime \prime}(\mathrm{Nb}-$ rich). For the natural aging of WQ-U6Nb alloy samples at ambient temperatures, the transformation sequence is proposed to be $\alpha^{\prime \prime}$-spinodal ordering $\rightarrow \alpha_{p o}$-phase decomposition $\rightarrow \alpha(U)+\alpha_{0}\left(U_{3} N b\right)$.

\section{Acknowledgements}

This work was performed under the auspices of the U. S. Department of Energy by the University of California, Lawrence Livermore National Laboratory under Contract No. W-7405-Eng-48. The authors gratefully acknowledge Anne Sunwoo, T. C. Sun, and Roger Kruger for the contributions of aging experiment, Vicki Mason-Reed for the work of microhardness measurement and optical metallography, and Rick Gross and Jessee Welch for the preparation of TEM foils.

\section{References}

1. Vandermeer, R.A., Acta Metall., 28 (1980), p. 383.

2. Eckelmeyer, K.H., Romig, A.D., and Weirick, L.J., Met. Trans. A, 15A (1984), p. 1319.

3. Koike, J., Kassner, M.E., and Tate R.E., D.E., Phase Diagrams of Binary Actinide Alloys, edited by Kassner, M.E. and Peterson, D.E., ASM International, 1995.

4. Vandermeer, R.A., Ogle, J.C., and Northcutt, Jr., W.G., Met. Trans. A, 12A (1981), p. 733.

5. Field R.D., Thoma D.J., Dunn, P.S., Brown D.W., Cady. C.M, Phil. Mag. A, 81 (2001), p. 1691.

6. Jackson, R.J., Miley, D. V., Trans. ASM, 61 (1968), p. 336.

7. Beverini, G., Edmonds, D.V., Colloque De Physique, Colloque C8, C8-429.

8. Cahn J.W., Trans. TMS of AIME, 242 (1968), p. 166.

9. Cahn J.W., Acta Metall., 9 (1961), p. 795. 
10. Hilliard, J.E., in "Phase Transformations,” (1970), ASM (Metals Park, OH), p. 497.

11. Tiapkin, Y.D., Ann. Rev. Mater. Sci., 7 (1977), p. 209.

12. Cahn J.W., Acta Metall., 10 (1962), p. 179.

13. Hsiung, L.M., Briant, C.L., Chasse, K.R., Mat. Res. Soc. Symp. Proc., Vol. 802 (2004), DD1.6.1

14. Sato K.and Stobbs, W.M., Phil. Mag. A, 69 (1994), 349.

15. Butler E.P. and Thomas, G., Acta Metall., 18 (1970), 347.

16. J.W. Edington, Practical Electron Microscopy in Materials Science, Van Nostrand Reinhold, New York, 1976.

17. Soffa, W.A.and Laughlinm D.E., in "Solid-State Phase Transformations," (1983), the Pittsburg Conference, ed. H.I. Aaronson, Met. Soc. AIME (Warrendale, PA), p. 159.

18. Porter, D.A. and Eastering, K.E., "Phase Transformations in Metals and Alloys" 2nd edition (1992), Chapman \& Hall. 